\title{
Elastic backscattering as a method for the measurement of the integral lithium content in thin films on fusion-relevant substrates
}

\author{
S. Krat ${ }^{1},{ }^{*}$, M. Mayer ${ }^{2}$, Ya. Vasina ${ }^{1}$, A. Prishvitsyn ${ }^{1}$, Yu. Gasparyan ${ }^{1}$, and A. Pisarev ${ }^{1}$ \\ ${ }^{1}$ National research nuclear university MEPhI, Moscow, Russia \\ ${ }^{2}$ Max Planck Institute for Plasma Physics, Garching, Germany
}

\begin{abstract}
Different ion beam analysis techniques for the study of thin lithium-containing layers on top of fusion relevant materials are discussed and compared to each other. Elastic backscattering analysis (EBS) with protons is determined to be one of the most promising techniques and allows measurements of Li layers with thicknesses from $\sim 100 \mathrm{~nm}$ up to $\sim 600 \mu \mathrm{m}$, as shown by SIMNRA simulations. The best sensitivity for thin films $(\sim 100 \mathrm{~nm})$ can be achieved using 4 $\mathrm{MeV}$ protons with $170^{\circ}$ scattering detection angle for layers on Mo and $\mathrm{W}$ substrates, and $2 \mathrm{MeV}$ for $\mathrm{C}$ substrates. Experimentally EBS measurements were successfully tested for Li films with thicknesses from $\sim 50 \mathrm{~nm}$ up to $\sim 400 \mathrm{~nm}$ after air exposure. The Li films become strongly inhomogeneous and require averaging over multiple measurements in nearby areas. This necessitates averaging over multiple nearby measurement points, and limits the overall precision of the measurement.
\end{abstract}

\section{Introduction}

Plasma Material Interactions in fusion devices have a crucial impact on plasma performance. It has been demonstrated, that the deposition of thin lithium films on plasma-facing components (PFCs) can improve the plasma performance by reducing the power threshold for access to high confinement modes (H-modes) [1-4]. Lithium has been also successfully used as plasma-facing material (PFM) in liquid limiters [5-8] and is considered to be used as liquid divertor material [9-11]. It has good compatibility with fusion plasmas due to its low nuclear charge, gettering of oxygen and carbon impurities, and it can improve the confinement and lowers hydrogen recycling resulting in low plasma edge densities in low recycling plasma regimes. The use of liquid lithium might potentially solve a number of challenges associated with classical solid plasma facing materials, such as melting, radiation damage, and accumulation of radioactive tritium. One of the important problems still to solve with regard to lithium use as PFM is the development of an effective method for collecting and recycling lithium eroded from a liquid lithium surface, transported through the fusion device, and then redeposited in some other area. Out of all liquid metals proposed for use as PFM, this is especially a problem for lithium due to its low melting point and low mass leading to high erosion and evaporation rates.

In order to study lithium transport and redeposition in fusion devices, quantitative measurement methods allowing the analysis of thin lithium-containing films on fusion relevant materials, such as tungsten, molybdenum, or stainless steels, are required [12-14]. Both in-situ and ex-situ analysis methods are difficult due to the low atomic weight of lithium, which makes measurements of mass, XPS, and EDS problematic. Besides, the high chemical reactivity of 
lithium can lead to damage of analytical equipment, for example mass spectrometers used in thermal desorption spectroscopy, limiting the possible amount of lithium used for analyses [15]. Ex-situ analysis is problematic due to the transformation of $\mathrm{Li}$ and $\mathrm{Li}-\mathrm{H}$ into $\mathrm{Li}_{2} \mathrm{CO}_{3}$ [16-19]. For macroscopic amounts of deposits on the scale of tens of $\mu \mathrm{g}$, chemical methods of analysis are available [20], while measurements of thin layers on the scale of several tens of nanometers, or localized deposits up to several tens of microns are challenging.

Ion beam analysis is a versatile family of techniques used for the analysis of solid surfaces and thin layers [21], containing analysis methods such as elastic backscattering spectrometry [22], elastic recoil detection analysis (ERDA) [23], and nuclear reaction analysis (NRA) [6]. Elastic backscattering spectrometry (EBS) is widely available in many laboratories and is nondestructive, economic, and reliable, meaning that it can provide repeatable quantitative measurements of the elemental composition of near-surface layers with an accuracy no worse than $10 \%$. This technique was already used successfully to study lithium-containing surfaces and materials $[6,22,24]$. However, optimization of the analysis parameters in order to maximize sensitivity and evaluation of some specific issues connected with lithium films on fusion relevant materials $[9,11,25-27]$ is required in order to maximize the effectiveness of the method, evaluate its limitations, and to be able to determine uncertainties and their main sources.

The use of ERDA for the detection of Li using incident 8.9 MeV oxygen ions has been recently reviewed in [23]. However, ERDA allows only the analysis of relatively thin layers, requires smooth surfaces, and gets technically challenging for larger samples or curved surfaces, as is often the case for PFCs.

For NRA the ${ }^{6} \mathrm{Li}\left(\mathrm{p},{ }^{3} \mathrm{He}\right){ }^{4} \mathrm{He}$ reaction has a relatively high cross section at energies above about 1.6 MeV [28-30]. However, the available cross section data for this reaction [31] are inconsistent and at backward angles the energy of the produced ${ }^{4} \mathrm{He}$ is below and the energy of the produced ${ }^{3} \mathrm{He}$ is only marginally above the incident energy due to the low Q-value of the reaction, rendering this reaction only marginally useful if Li films on heavy substrates should be investigated. The reaction ${ }^{7} \mathrm{Li}(\mathrm{p}, \alpha)^{4} \mathrm{He}$ has a very high $\mathrm{Q}$-value of $17.3 \mathrm{MeV}$, resulting in reaction products with energies well above the incident energy. The cross section is above $1 \mathrm{mb} / \mathrm{sr}$ in the energy range $1.5-3.5 \mathrm{MeV}$ with a maximum value of about $6 \mathrm{mb} / \mathrm{sr}$ around $2.7 \mathrm{MeV}$ [32]. This reaction is usable for the detection of $\mathrm{Li}$, but usually will require a large solid-angle detector. Filtering of unwanted backscattered protons from a heavy substrate using a simple stopper foil limits the incident proton energy to values below about $1.5 \mathrm{MeV}$, as otherwise both backscattered protons and created ${ }^{4} \mathrm{He}$ ions will penetrate the foil. The cross section is very low at these low energies, and the detection of other light elements, especially $\mathrm{C}$ and $\mathrm{O}$, may require either additional measurements, or installation of additional detectors for simultaneous EBS measurements, which would also face the issue of high background signal. I.e. NRA with incident protons for the detection of $\mathrm{Li}$ is possible, but shows problems.

Another possibility for detecting ${ }^{6} \mathrm{Li}$ is the ${ }^{6} \mathrm{Li}(\mathrm{d}, \mathrm{p})^{7} \mathrm{Li}$ reaction [30,33,34]. However, the associated ${ }^{7} \mathrm{Li}(\mathrm{d}, \alpha \mathrm{n}) \alpha$ reaction is a three-body reaction with only limited use for NRA.

It is also possible, if logistically more complex due to the difficulties of purchasing ${ }^{3} \mathrm{He}$ in some countries, to use ${ }^{3} \mathrm{He}^{+}$ions for detecting ${ }^{6} \mathrm{Li}$. Either ${ }^{6} \mathrm{Li}\left({ }^{3} \mathrm{He}^{+}, \mathrm{p}_{0}\right){ }^{8} \mathrm{Be}[35,36]$ or ${ }^{6} \mathrm{Li}\left({ }^{3} \mathrm{He}^{+}, \mathrm{p}_{1}\right)^{8} \mathrm{Be}$ [36,37] reactions could be used. Both these reactions have high Q-values of $16.8 \mathrm{MeV}$ and 13.9 $\mathrm{MeV}$, respectively. The ${ }^{6} \mathrm{Li}\left({ }^{3} \mathrm{He}^{+}, \mathrm{p} 0\right)^{8} \mathrm{Be}$ cross section is known for multiple detection angles from $90^{\circ}$ to $155^{\circ}$ only at ${ }^{3} \mathrm{He}^{+}$energies below $1.85 \mathrm{MeV}$, and is below $1 \mathrm{mb} / \mathrm{sr}$ in that energy range, with the highest value of $0.9 \mathrm{mb} / \mathrm{sr}$ at $155^{\circ}$ observation angle for $1.85 \mathrm{MeV}^{3} \mathrm{He}^{+}$. For 
higher energies it is known only for $150^{\circ}$ detection angle [36], and the maximum cross section value is only $2.8 \mathrm{mb} / \mathrm{sr}$ at $5.08 \mathrm{MeV}^{3} \mathrm{He}^{+}$. For $\left.{ }^{6} \mathrm{Li}^{3}{ }^{3} \mathrm{He}^{+}, \mathrm{p} 0\right)^{8} \mathrm{Be}$, the cross section is also known for multiple angles from $99^{\circ}$ to $150^{\circ}$ only at ${ }^{3} \mathrm{He}^{+}$energies below $1.85 \mathrm{MeV}$ [37]. The maximum cross section value is $\sim 4 \mathrm{mb} / \mathrm{sr}$ for $1.7 \mathrm{MeV}{ }^{3} \mathrm{He}^{+}$at $150^{\circ}$ observation angle. At higher ${ }^{3} \mathrm{He}^{+}$ energies it is known only for $150^{\circ}$ detection angle [36], with cross section values between 3 and $4.3 \mathrm{mb} / \mathrm{sr}$. Low cross section values, as well as natural scarcity of ${ }^{6} \mathrm{Li}(7.5$ at.\% for the natural isotopic ratio of $\mathrm{Li}$ ) will require a large solid-angle detector. The detection is also further complicated due to the immediate fission reaction with high Q-value of ${ }^{8} \mathrm{Be}$ to ${ }^{8} \mathrm{Be} \rightarrow{ }^{4} \mathrm{He}+{ }^{4} \mathrm{He}+18.07 \mathrm{MeV}$.

Due to the described difficulties of ERDA and NRA, the optimization of parameters for the measurement of lithium films on molybdenum, tungsten, stainless steel, Inconel, and carbon by means of EBS is discussed in this paper. Specific features of thin lithium films on those materials after a prolonged exposure to atmospheric air are demonstrated. Experimental results on lithium compounds on molybdenum are given.

\section{Experimental}

\subsection{Optimal parameters for EBS analysis}

For EBS analysis, only hydrogen isotopes or helium ions can be used to analyze lithiumcontaining surface layers. Of the available hydrogen and helium isotopes, analysis with protons allows a large depth of analysis.

Both ${ }^{7} \mathrm{Li}$ and ${ }^{6} \mathrm{Li}$ can be detected by means of EBS, and a number of cross sections are available both for hydrogen and helium backscattering [31]. The backscattering cross sections for both elements are comparable in magnitude. However, ${ }^{7} \mathrm{Li}$ prevails in the natural isotopic mixture $(92.5 \%)$, rendering it easier detectable.

\subsubsection{Thin layer analysis}

Cross sections for proton backscattering from $\mathrm{Li}, \mathrm{C}$ and $\mathrm{O}$ are shown in fig. 1 for an observation angle of $170^{\circ}$ in the laboratory system. This observation angle was chosen as the largest observation angle available in [31] for ${ }^{7} \mathrm{Li}(\mathrm{p}, \mathrm{p} 0)^{7} \mathrm{Li}$ back-scattering.

In general, the ${ }^{7} \mathrm{Li}(\mathrm{p}, \mathrm{p} 0){ }^{7} \mathrm{Li}$ backscattering cross section does not depend strongly on the observation angle within the range $160^{\circ}$ to $170^{\circ}$ (see fig. 2). The cross section for ${ }^{7} \mathrm{Li}(\mathrm{p}, \mathrm{p} 0)^{7} \mathrm{Li}$ was multiplied by 2 and the cross section for $16 \mathrm{O}(\mathrm{p}, \mathrm{p} 0) 16 \mathrm{O}$ was multiplied by 3 in order to represent effective cross sections for analysis of the $\mathrm{Li}_{2} \mathrm{CO}_{3}$ compound.

Cross sections for ${ }^{7} \mathrm{Li}(\mathrm{p}, \mathrm{p} 0)^{7} \mathrm{Li}$ obtained from [31,32] are the most complete in the energy range from 1.5 to $7 \mathrm{MeV}$. The parameters of all datasets available in [31] for the observation angles from $160^{\circ}$ to $170^{\circ}$ are given in table 1 . For the datasets from [38,39] uncertainties are not available, for the datasets from [28,40], uncertainties are given for the whole datasets, while for the dataset from [32] uncertainties are given for each individual measurement. Dataset [32] is the only one with consistent energy resolution. As such, dataset [32] was chosen for use. 
Table 1. Characteristics of available ${ }^{7} \mathrm{Li}(\mathrm{p}, \mathrm{p} 0)^{7} \mathrm{Li}$ cross section datasets for observation angles from $160^{\circ}$ to $170^{\circ}$.

\begin{tabular}{|c|c|c|c|c|}
\hline Dataset & $\begin{array}{l}\text { Observation } \\
\text { angle, }\end{array}$ & $\begin{array}{l}\mathrm{p}^{+} \text {energy } \\
\text { range } \\
\text { covered, } \mathrm{MeV}\end{array}$ & $\begin{array}{l}\text { Energy } \\
\text { resolution, } \mathrm{keV}\end{array}$ & Uncertainty, \% \\
\hline $\begin{array}{l}\text { S. Bashkin and } \\
\text { H.T. Richards } \\
(1951) \text { [28] }\end{array}$ & $164^{\circ}$ & $0.87-3.66$ & $\begin{array}{l}7 \text { to } 193, \\
\text { average of } 30\end{array}$ & 20 \\
\hline $\begin{array}{ll}\text { Malmberg, } & \text { P.R. } \\
(1956)[40] & \end{array}$ & $165^{\circ}$ & $1.34-2.75$ & $\begin{array}{l}6 \text { to } 104, \\
\text { average of } 27\end{array}$ & 10 \\
\hline $\begin{array}{l}\text { U. Fasoli et al. } \\
\text { (1964) [38], }\end{array}$ & $166.2^{\circ}$ & $1.23-5.51$ & $\begin{array}{l}12 \text { to } 67, \\
\text { average of } 27\end{array}$ & Not given \\
\hline $\begin{array}{llr}\text { K.Kilian et } & \text { al } \\
(1969) & & \text { (in } \\
\text { German) } & \text { [39] } & \end{array}$ & $160.2^{\circ}, 170^{\circ}$ & $3.10-10.30$ & $\begin{array}{l}1150 \text { to } 4150, \\
\text { average } \\
1950\end{array}$ & Not given \\
\hline $\begin{array}{l}\text { V. Paneta et al. } \\
(2012) \text { [32] }\end{array}$ & $160^{\circ}, 170^{\circ}$ & $1.50-7.00$ & $\begin{array}{l}25 \text { from } 1.8 \text { to } \\
2.2 \mathrm{MeV}, \\
100 \text { from } \\
500 \text { from } 4.8 \text { to } \\
5.7 \mathrm{MeV}\end{array}$ & $\begin{array}{l}<4 \%, \quad \text { individual } \\
\text { measurement } \\
\text { uncertainties provided }\end{array}$ \\
\hline
\end{tabular}

Cross sections for $12 \mathrm{C}(\mathrm{p}, \mathrm{p} 0) 12 \mathrm{C}$ backscattering in the proton energy range of $0.3-7 \mathrm{MeV}$ are based on SigmaCalc calculations [41]. SigmaCalc calculations datasets do not contain uncertainties [41]. Cross sections for ${ }^{16} \mathrm{O}(\mathrm{p}, \mathrm{p} 0)^{16} \mathrm{O}$ were based on SigmaCalc calculations [41] for energies from $1.5 \mathrm{MeV}$ to $4.08 \mathrm{MeV}$ and experimentally obtained [42] for energies up to 5.66 $\mathrm{MeV}$. It should be noted that the experimental data are only available for $160^{\circ}$ scattering angle for such high energies. Dataset [42] is given with an R.M.S. error in the measurement of cross sections $\sim 3.2 \%$, and statistical error of $\sim 5 \%$. 


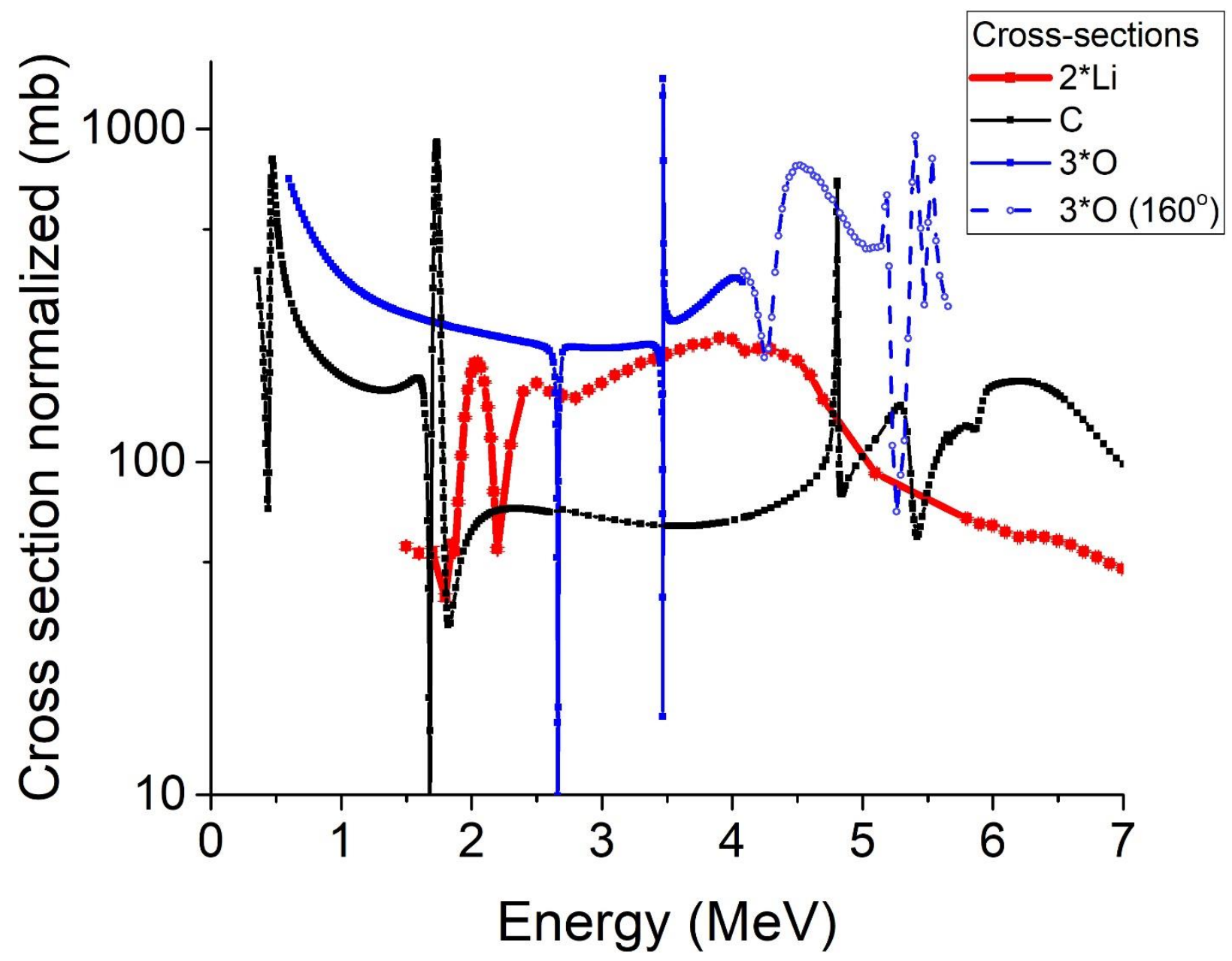

Fig. 1. Cross sections of protons backscattering from ${ }^{7} \mathrm{Li},{ }^{12} \mathrm{C}$, and ${ }^{16} \mathrm{O}$ at a scattering angle of $170^{\circ}$ in the laboratory system, normalized to $\mathrm{Li}_{2} \mathrm{CO}_{3}$ stoichiometry. For $\mathrm{O}$ at proton energies above $4 \mathrm{MeV}$, data are shown for the closest available angle $\left(160^{\circ}\right)$ as blue dashed line. 


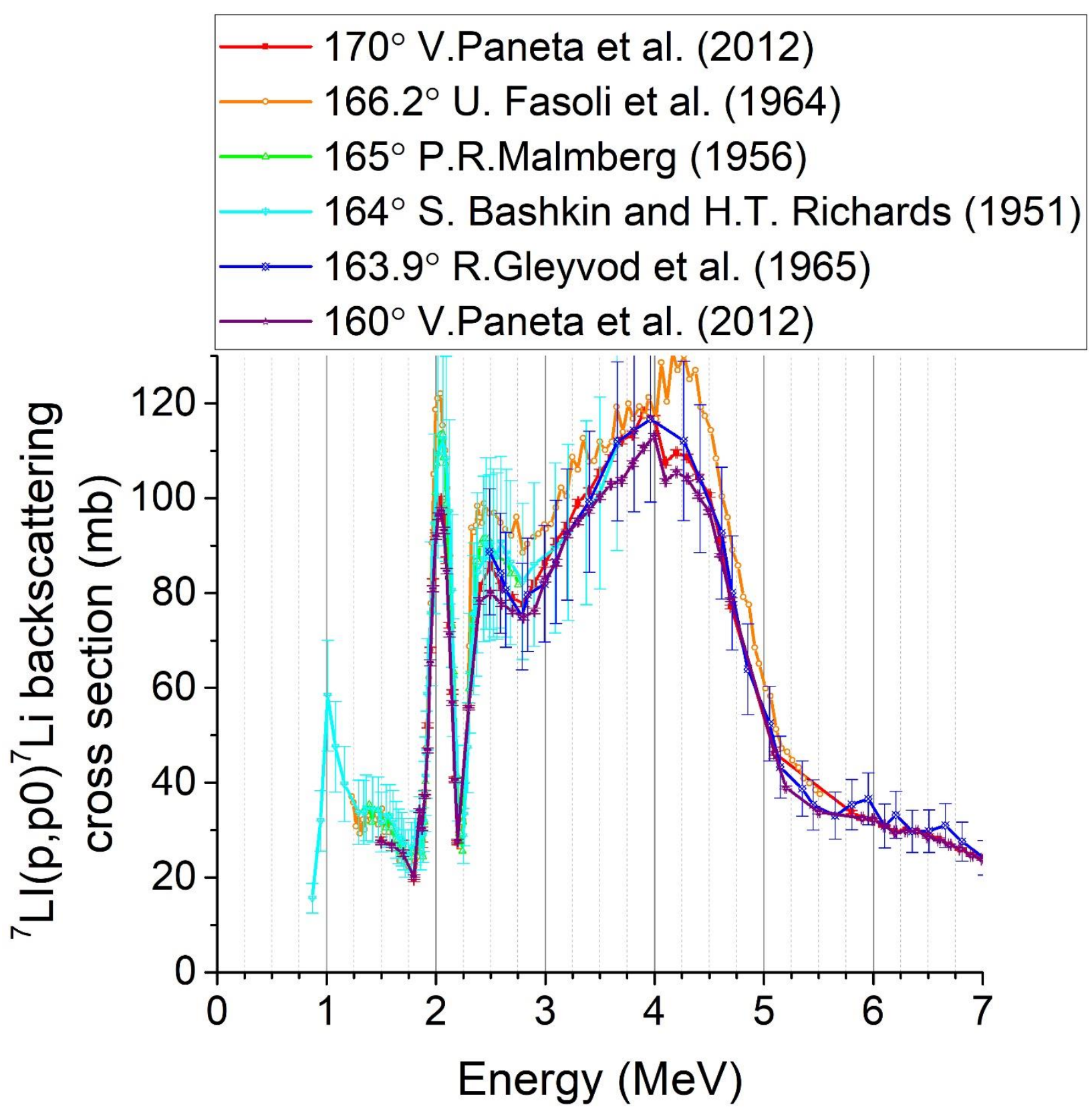

Fig. 2. Cross sections for ${ }^{7} \mathrm{Li}(p, p 0)^{7}$ Li back-scattering: red-170 observation angle, $\mathrm{V}$. Paneta et al. (2012) [32], orange - $166.2^{\circ}$ observation angle, U. Fasoli et al. (1964) [38], green - $165^{\circ}$ observation angle, Malmberg, P.R. (1956) [40], cyan - $164^{\circ}$ observation angle, S. Bashkin and H.T. Richards (1951) [28], blue - 163.9 observation angle, R. Greyvod et al. (1965) [43], purple $-160^{\circ}$ observation angle, V. Paneta et al. (2012) [32].

The $\mathrm{Li}$ cross section has two peaks at proton energies of $\sim 2$ and $\sim 4 \mathrm{MeV}$. In order to maximize the accuracy of the analysis of thin Li films, the $\mathrm{Li}$ signal should be maximized while simultaneously the substrate signal should be minimized. For heavy substrates, such as molybdenum or tungsten, cross sections for proton backscattering can be assumed to be Rutherford and decrease with increasing energy, while the maximal cross sections for $\mathrm{Li}$ are around $4 \mathrm{MeV}$. Consequently, analysis at about $4 \mathrm{MeV}$ incident energy is the most efficient, assuming dual and multiple scattering can be simulated or measured with sufficient precision and sufficiently precise data for substrate stopping powers are known. 
In the case of SS and Inconel substrates, where proton backscattering from substrate elements cannot be adequately described by the Rutherford formula, the situation is more uncertain. The cross sections for $56 \mathrm{Fe}(\mathrm{p}, \mathrm{p} 0) 56 \mathrm{Fe}$ and $\mathrm{Ni}(\mathrm{p}, \mathrm{p} 0) \mathrm{Ni}$ are only known up to $3.3 \mathrm{MeV}$ and $2.85 \mathrm{MeV}$, respectively. Therefore, analysis at higher energies can not be performed.

In the case of carbon substrate, the cross section for $12 \mathrm{C}(\mathrm{p}, \mathrm{p} 0) 12 \mathrm{C}$, is known in a wide range of energies up to $7 \mathrm{MeV}$, but strongly deviates from Rutherford, as can be seen in fig. 1 .

In order to determine the best energy for analysis of Li layers on carbon, SS and Inconel substrates, computer modeling using the SIMNRA code [44] with SRIM 2013 [45] stopping powers was used to simulate EBS spectra of $100 \mathrm{~nm} \mathrm{Li}_{2} \mathrm{CO}_{3}$ on $\mathrm{C}$, SS and Inconel for proton energies from 1.5 to $3.3 \mathrm{MeV}$ in the case of SS substrate, $2.85 \mathrm{MeV}$ in the case of Inconel substrate and $7 \mathrm{MeV}$ for $\mathrm{C}$ substrate, with a detection angle of $170^{\circ}$. The thickness of $100 \mathrm{~nm}$ was chosen as a characteristic thickness of "thin" layers, where the energy loss is negligible. The results of these calculations are shown in fig. 3. It can be seen that the best energy for analysis is 3.3 MeV for SS substrate, $2.85 \mathrm{MeV}$ for Inconel substrate, and $2 \mathrm{MeV}$ for $\mathrm{C}$ substrate. For these energies the ratios of Li signal to substrate signal are $\sim 0.06,0.05$ and 0.11 , respectively. This means that the measurement of the lithium content in a $100 \mathrm{~nm}$ thick lithium film with a statistical error below $10 \%$ at least 1766, 2100, and 1000 counts must be accumulated under the $\mathrm{Li}$ peak in the EBS spectrum for SS, Inconel, and C substrates, respectively. 


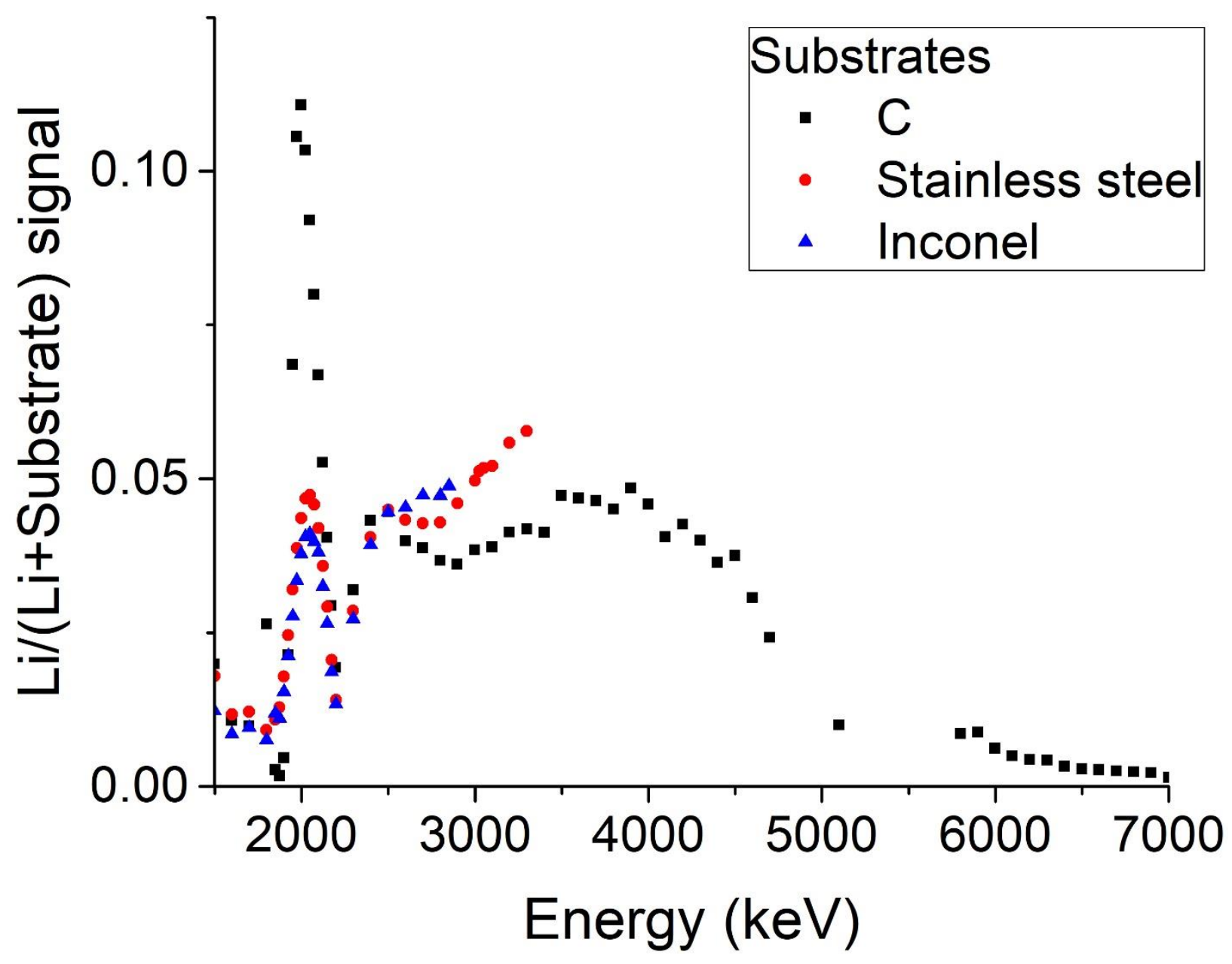

Fig. 3. Ratios of EBS signals from a $100 \mathrm{~nm}$ Li film to the net signals from Li and substrate for carbon, stainless steel, and Inconel substrates as a function of incident proton energy for a scattering angle of $170^{\circ}$.

It should be also noted that for very thin layers, i.e. below the $\mathrm{Li}$ detection limit, one could potentially use the resonance peak for oxygen at $3.5 \mathrm{MeV}$ to indirectly detect $\mathrm{Li}$ in $\mathrm{Li}_{2} \mathrm{CO}_{3}$ layers due to the very high elastic cross section. Obviously, this method can only be used if the assumption of a Li2CO3 stoichiometry is fulfilled and there are no other sources of oxygen in the sample (e.g. adsorbed oxygen and oxides).

In order to achieve a complete reaction of $\mathrm{Li}$ films to $\mathrm{Li} 2 \mathrm{CO} 3$, significant time has to pass between exposure of the Li layer to atmosphere and analysis. Upon exposure to atmospheric air close to room temperature, $\mathrm{Li}$ and $\mathrm{Li}-\mathrm{H}$ react with all of atmospheric main components $\left(\mathrm{N}_{2}\right.$ $\left.[46,47], \mathrm{O}_{2}, \mathrm{H}_{2} \mathrm{O}[48-50], \mathrm{CO}_{2}[18,51]\right)$ in a complex reaction chain. In these reactions, humidity plays a critical role $[17,46,52]$. Already the presence of $10^{-3}$ mass $\%$ of water vapor in air increases the reaction rate with N2 significantly, and some literature suggests that the presence of hydrogen in the atmosphere might suppress reactions with $\mathrm{N} 2$ with $\sim 10 \%$ hydrogen concentration being enough to completely suppress these reactions [52]. Both $\mathrm{Li}_{3} \mathrm{~N}$ [53] and $\mathrm{Li}_{2} \mathrm{O}[17,48]$ react with $\mathrm{H}_{2} \mathrm{O}$ in turn, transforming into $\mathrm{LiOH} . \mathrm{Li}_{2} \mathrm{O}[54,55]$ and $\mathrm{LiOH}[56]$ react with $\mathrm{CO} 2$, resulting in $\mathrm{Li} 2 \mathrm{CO} 3$, which is thus the final product of $\mathrm{Li}$ and $\mathrm{Li}-\mathrm{H}$ interacting with atmospheric air. In the case of persistent high humidity $(>80 \%)$, $\mathrm{Li} 2 \mathrm{CO} 3 \cdot \mathrm{OH}$ can be expected to be the end-product [17]. As such, providing that sufficient time has passed between Li layer's exposure to atmospheric air and the sample has been kept in atmosphere with low humidity, 
Li2CO3 stoichiometry can be assumed. In other cases, the presences of oxygen and carbon can still serve as indicators of $\mathrm{Li}$ presence, while the presence of nitrogen might indicate that only a small time has passed between atmospheric exposure and analysis, and the Li-containing layer is still in the process of reacting with atmospheric air.

\subsubsection{Evaluation of $\mathrm{Li}$ content in thick layers}

For thick Li-containing layers, a correct simulation requires a precise knowledge of layer's stopping power. An estimate of the total thickness of the layer can be made based on the knowledge of the layer stopping power rather than on the knowledge of the cross sections of the components of the layer. There are two main ways to measure the total thickness of a layer.

Firstly, one can measure the positions of both high energy and low energy fronts of EBS peaks of elements in the Li-containing layer (fig. 4a). For pure Li layers, due to low stopping power of $\mathrm{Li}$, thicknesses of even extremely thick layers of more than $100 \mu \mathrm{m}$ can be measured. Such thicknesses are outside the usual range of EBS applications, and can find application in the study of (large) lithium dust particles, which could be observed through their whole structure, or surface processes in bulk Li objects.

Secondly, one can analyze the high energy front of the EBS signal of elements present only in the substrate (fig. 4b). Maximum thicknesses of pure Li layers, which can be measured on various fusion-relevant substrates by both the above-described methods, are shown in fig. 5 . The uncertainty of these methods arises from the uncertainty of the SRIM stopping power, which is $\sim 4 \%$ [57], and from the uncertainty generated by individual specifics of the measurement setup and operator's skill which determine how well the edge can be identified in the spectrum. For the purpose of this paper, this uncertainty is suggested to be $\sim 5 \%$, for a combined uncertainty of $\sim 7 \%$.

In general, the second method allows measurement of even thicker layers than the first one. Substrates made of heavy elements, such as molybdenum or tungsten, allow measurement of thicker layers than substrates made of lighter materials, such as steels. 

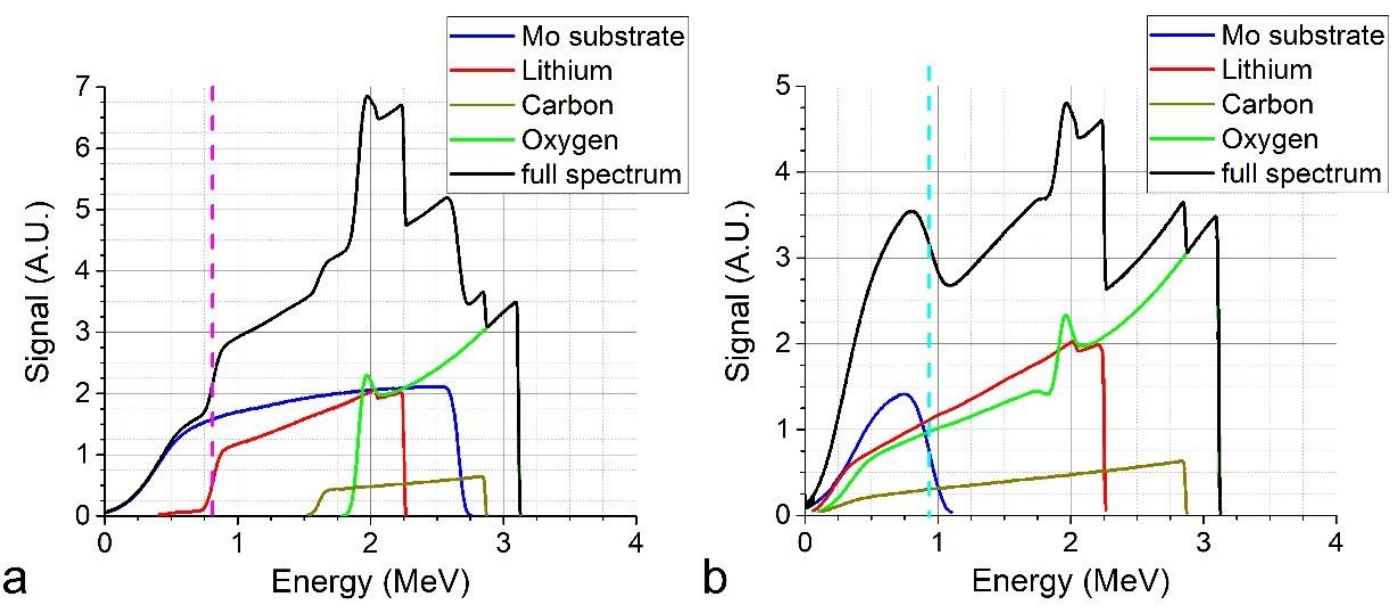

Fig. 4. An example of a modeled EBS spectrum of a thick homogenous Li2CO3 layer (4 MeV protons at normal incidence, $170^{\circ}$ observation angle) on a Mo substrate, where the thickness of the layer is calculated from a) the position of the low energy front of the Li signal (magenta dashed line) or b) the position of the high energy front of the substrate (Mo) signal (cyan dashed line). Total layer thickness is a) $30 \mu \mathrm{m}$, b) $58 \mu \mathrm{m}$. Blue line - Mo signal, red-Li, dark yellow - C, green-O, black - total signal

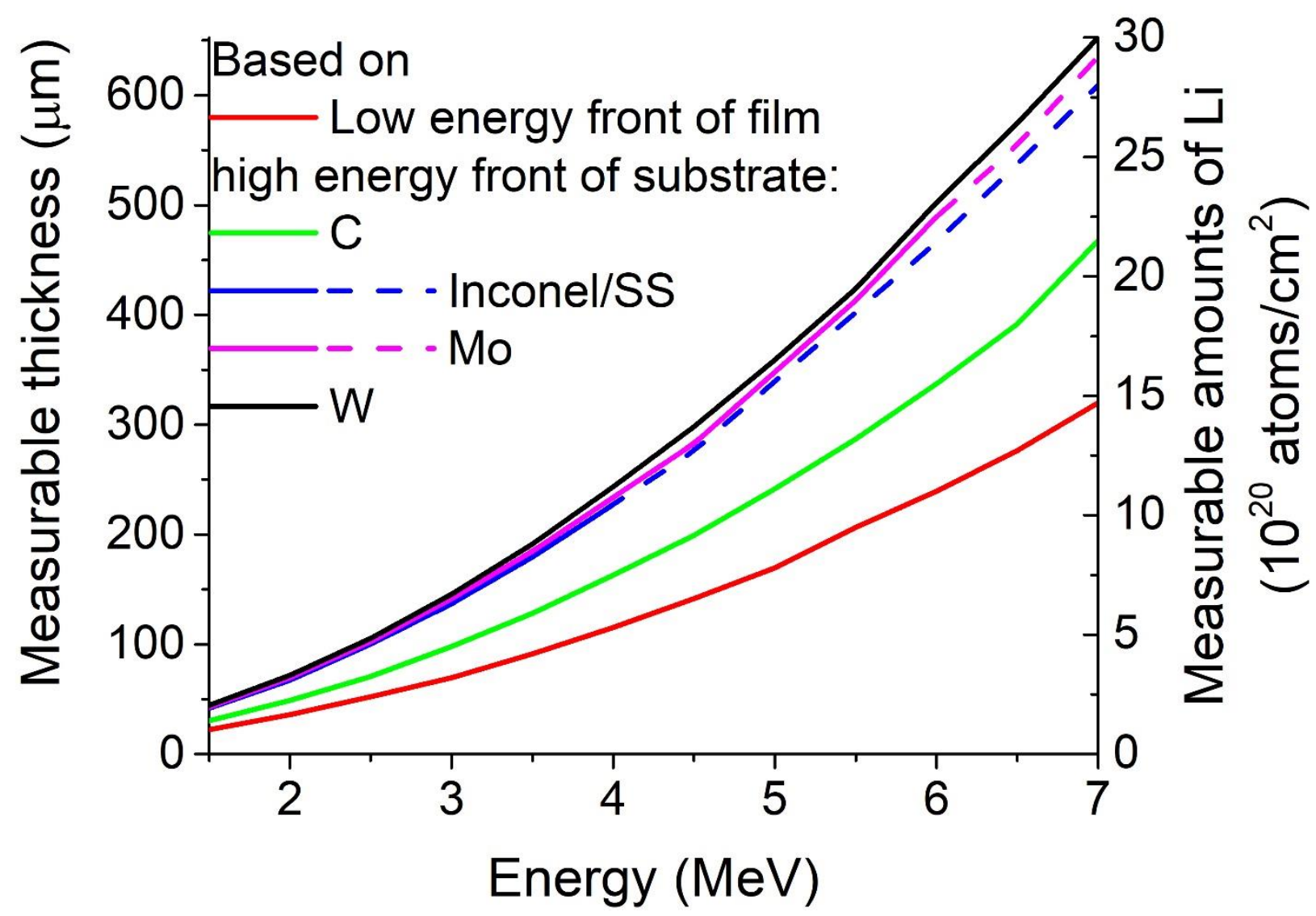

Fig. 5. Maximum thicknesses of Li layer which can be measured for different proton energies. Dashed lines indicate thicknesses calculated in the proton energy ranges where data is not available for cross section of proton backscattering on substrate. Uncertainty must be taken as $\sim 7 \%$. 
Nickel is the heaviest element both in Inconel and in stainless steel. This means that, for these substrates, the maximum measurable thickness of $\mathrm{Li}$ is the same. Unfortunately, there is no cross section data available for $\mathrm{Ni}(\mathrm{p}, \mathrm{p}) \mathrm{Ni}$ backscattering. For the purposes of modeling the Rutherford backscattering cross section was used, which becomes inaccurate for proton energies starting from $4 \mathrm{MeV}$ if energy losses in the Li layer are considered. Therefore, the values given in fig. 5 are somewhat inaccurate. Stainless steel, which is used, as well as most common stainless steels, comprises at most only $\sim 10$ at. \% of Ni. Therefore, the Fe signal can be used instead of $\mathrm{Ni}$, which gives virtually the same thickness limit due to very close atomic masses of $\mathrm{Fe}$ and $\mathrm{Ni}$. Proton backscattering cross sections for Fe are only available up to $3.3 \mathrm{MeV}$, which means that the data is inaccurate for proton energies above $4.5 \mathrm{MeV}$.

For Mo substrate the Rutherford cross section becomes inaccurate at energies above $4.2 \mathrm{MeV}$, which, accounting for energy losses in Li-containing layer, means that the results in fig. 5 may be inaccurate for proton energies above $6 \mathrm{MeV}$.

After prolonged exposure to atmospheric air, pure $\mathrm{Li}$ layer transforms gradually into $\mathrm{Li}_{2} \mathrm{CO}_{3}$ in a complex multi-stage process [16], starting with fast reaction with water vapor [58]. The stopping power of $\mathrm{Li}_{2} \mathrm{CO}_{3}$ is different from that of pure $\mathrm{Li}$, which means that differing amounts of $\mathrm{Li}$ atoms initially deposited on the surface in the fusion device can be measured. Maximum thicknesses of $\mathrm{Li}_{2} \mathrm{CO}_{3}$ layers, as well as amounts of $\mathrm{Li}$ atoms corresponding to them, which can be measured on various fusion-relevant substrates, are shown in fig. 6 . The maximum proton energy used was $5.7 \mathrm{MeV}$, as the cross section for $\mathrm{O}$ is not available above this energy, except for the measurements based on the low energy front of the $\mathrm{Li}$ signal. $1 \mathrm{~nm}$ of Li2CO3 corresponds to $3.44 \times 10^{15}$ atoms $/ \mathrm{cm}^{2}$ of $\mathrm{Li}$. 


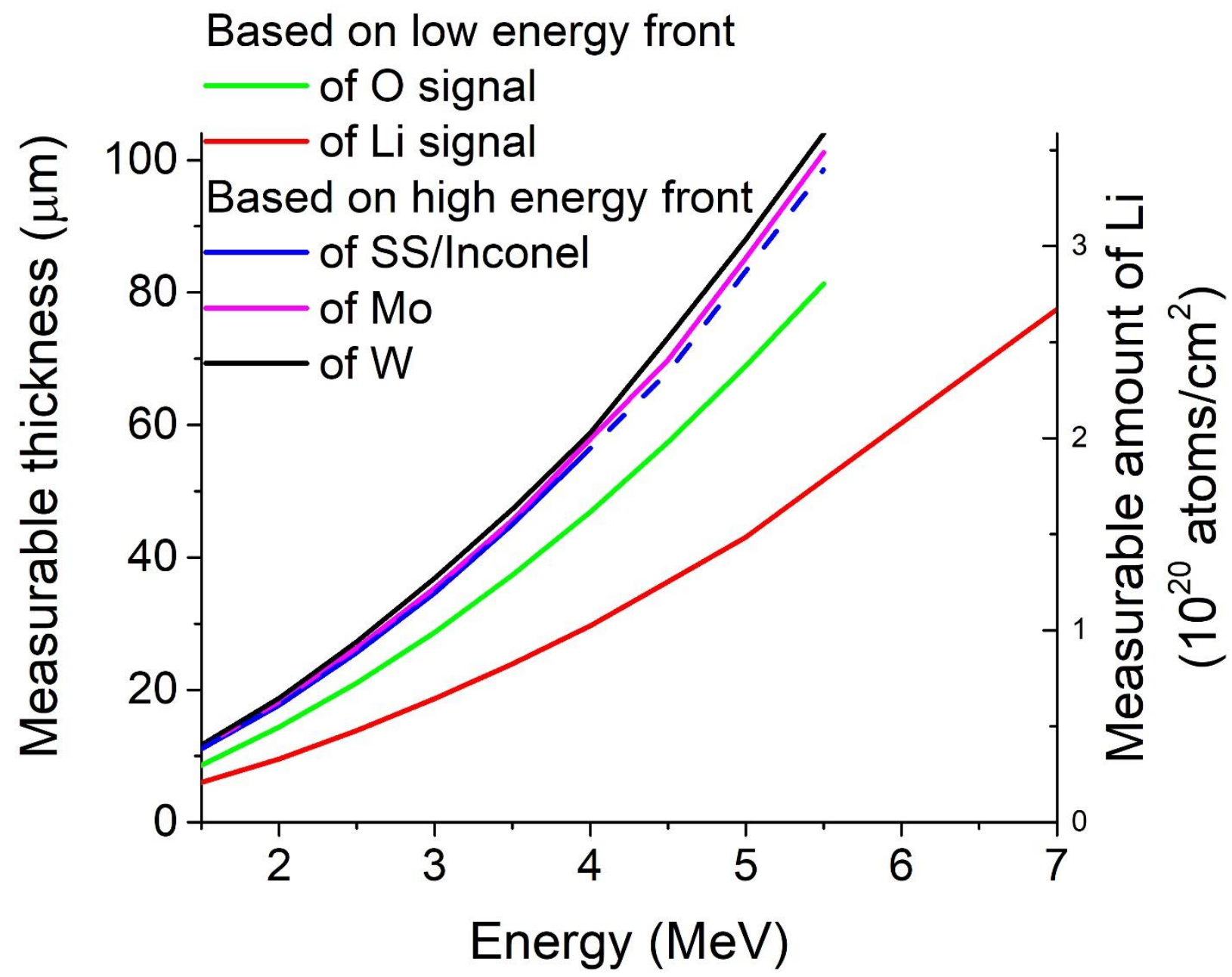

Fig. 6. Maximum thicknesses of $\mathrm{Li}_{2} \mathrm{CO}_{3}$ layer which can be measured for different proton energies. Dashed lines indicate thicknesses calculated in the proton energy ranges where data is not available for cross section of proton backscattering on substrate. The values based on the lower energy front of the $O$ signal and on the high energy fronts of substrates require the assumption of a homogenous Li2CO3 stoichiometry for the whole layer. The uncertainty should be taken as $\sim 7 \%$.

Different maximum thicknesses can be measured using different peaks of elements in the $\mathrm{Li}_{2} \mathrm{CO}_{3}$ layer. It is most reliable to use $\mathrm{Li}$ itself. However, for $\mathrm{Li} 2 \mathrm{CO} 3$, the use of $\mathrm{Li}$ signal is possible only at the lowest thicknesses and at energies below $\sim 2.5 \mathrm{MeV}$. This is because the Li signal is low compared to the signals of the substrates to reliably observe the low energy edge of the Li EBS peak. Thicknesses of thicker Li-containing layers can be measured using oxygen relying on the assumption that the layer completely transformed to $\mathrm{Li} 2 \mathrm{CO} 3$ due to reactions with air. One has to assume that stoichiometry is the same through the whole layer, as the lower energy front of $\mathrm{Li}$ signal cannot be seen in this situation. The use of carbon is not recommended due to its low content and the low cross section, compared to Li and $\mathrm{O}$.

Comparing the measurable amounts of $\mathrm{Li}$ in pure $\mathrm{Li}$ and in $\mathrm{Li} 2 \mathrm{CO} 3$ layers, one can say that prolonged exposure to atmospheric air reduces the maximum measurable amount of Li by a factor of about 5, as can be seen by comparing the data in fig. 5 and 6 (right y-axes). In any case the measureable thicknesses of these layers are far beyond expected layer thicknesses and even far beyond typical thicknesses normally used in EBS analyses. Realistically, for such thick films, 
flaking and cracking due to chemical reactions with atmospheric air are more likely to be the limitation rather than the EBS-inherent limitations.

For layer thicknesses not exceeding maximum measurable thicknesses of Li2CO3 layers based on the low energy front of $\mathrm{Li}$ peak, depth profiling of elemental composition is possible throughout their thickness. The stopping power of $\mathrm{Li} 2 \mathrm{CO} 3$ is the highest among all likely products of $\mathrm{Li}$ and $\mathrm{Li}-\mathrm{H}$ reacting with atmospheric air (see table 2), and $\mathrm{Li}$ has the lowest mass (besides that of $\mathrm{He}$ and $\mathrm{H}$ isotopes). This means, that if the lower energy front of the Li peak in a Li2CO3 layer can be observed, then the lower energy fronts of all other element's peaks in all other products of Li reactions with atmospheric air could also be observed, and depth profiling could be performed.

Table 2. Stopping powers of Li compounds that can be produced as results of contact with atmospheric air relative to the stopping power of Li2CO3, in the energy range from 1.5 to $7 \mathrm{MeV}$

\begin{tabular}{|l|l|}
\hline Compound & Relative stopping power \\
\hline $\mathrm{Li}_{2} \mathrm{CO}_{3}$ & 1 \\
\hline $\mathrm{Li}_{2} \mathrm{O}$ & 0.8 \\
\hline $\mathrm{Li}_{3} \mathrm{~N}$ & 0.7 \\
\hline $\mathrm{LiOH}$ & 0.7 \\
\hline $\mathrm{Li}_{2} \mathrm{NH}$ & 0.6 \\
\hline $\mathrm{Li}$ & 0.6 \\
\hline $\mathrm{LiNH}$ & 0.5 \\
\hline $\mathrm{LiH}$ & 0.4 \\
\hline
\end{tabular}

Evaluation of depth profiles and quantities of hydrogen and helium isotopes in Li layers ex-situ is more complicated. It is impossible to detect ${ }^{1} \mathrm{H}$ by means of EBS. Using proton backscattering to measure $\mathrm{D}$ and He content is possible, but ill-advised due to their low relative masses. The widest range of energies $\mathrm{D}\left(\mathrm{p}, \mathrm{p}_{0}\right) \mathrm{D}$ cross section is known in spans from $1.8 \mathrm{MeV}$ to $3.2 \mathrm{MeV}$ for the detection angle of $165^{\circ}$ with an uncertainty of 7.5\% [59]. Only one dataset for ${ }^{3} \mathrm{He}\left(\mathrm{p}, \mathrm{p}_{0}\right)^{3} \mathrm{He}$ cross section is given in [31], and only known for energies from $1.5 \mathrm{MeV}$ to $2.8 \mathrm{MeV}$ with a detection angle of $159.2^{\circ}$ and a stated uncertainty of $\pm 2 \%$ [60]. For ${ }^{4} \mathrm{He}\left(\mathrm{p}, \mathrm{p}_{0}\right)^{4} \mathrm{He}$ back scattering, a SigmaCalc evaluation is available in the $\mathrm{p}^{+}$energy range from $0.5 \mathrm{MeV}$ to $6 \mathrm{MeV}$. Based on the position of the low energy front of $4 \mathrm{He}$ signal being detectable, ${ }^{4} \mathrm{He}$ can be depth profiled up to $78 \mu \mathrm{m}$ in $\mathrm{Li}_{2} \mathrm{CO}_{3}$, and up to $110 \mu \mathrm{m}$ in metallic $\mathrm{Li}$ using $6 \mathrm{MeV} \mathrm{p}^{+}$.

For D and ${ }^{3} \mathrm{He}$ depth profiling up to large depths, additional measurements by NRA might be performed using $3 \mathrm{He}$ or D ions respectively [61]. However, the $\mathrm{D}\left({ }^{3} \mathrm{He}, \mathrm{p}\right){ }^{4} \mathrm{He}$ reaction peak can overlap with the ${ }^{6} \mathrm{Li}(3 \mathrm{He}, \mathrm{p} 1)^{8} \mathrm{Be}$ reaction peak [36,37] for thick layers. If $\mathrm{Li}$ depth profile can be established by means of EBS, then $\mathrm{D}$ and ${ }^{3} \mathrm{He}$ depth profiles can be established with more precision.

It should be noted that for deuterium, it has been previously shown that no deuterium remains in $\mathrm{Li}$ layer after prolonged exposure to atmospheric air [16], and that at least some stages in $\mathrm{Li}-\mathrm{H}$ transformation to Li2CO3 are not diffusion-controlled [50]. As such, a clear separation into a Dcontaining bottom layer (close to the substrate) and a D-free upper layer (closer to atmosphere) cannot be assumed. 


\subsection{Experimental analysis}

A selection of lithium films was deposited on Mo substrates using the MD-2 installation [62]. The films were deposited by magnetron sputtering of a liquid Li cathode based on a capillary porous system similar to the ones used in the T-11M tokamak [63], using $99.98 \%$ pure $\mathrm{D}_{2}$ as working gas. The background pressure was about $3 \times 10^{-5} \mathrm{~Pa}$, the working pressure was about 3 $\mathrm{Pa}$, the distance between the Li cathode and the Mo substrate was $\sim 10 \mathrm{~cm}$. Substrate deposition temperatures were varied from room temperature to $350^{\circ} \mathrm{C}$ for ex-situ analysis in order to check the theoretical predictions. A wide range of deposition temperatures was chosen to study differences in Li films deposited at various fusion relevant conditions in order to check if the issues with their analysis would be the same. The thicknesses of the films varied from $\sim 50 \mathrm{~nm}$ to $\sim 400 \mathrm{~nm}$ based on quartz microbalance (QMB) in-situ measurements. Gold plated quartz crystals were used to prevent chemical reaction of the QMB crystal electrodes with Li. The deposition setup is shown in fig. 7. Due to geometric limitations of the deposition chamber, it was impossible to place the QMB in the same position relative to the magnetron target as the sample. The distance of the QMB crystal to the liquid Li target was $\sim 85 \mathrm{~mm}$, the distance from the Mo substrate to the Li target was $\sim 110 \mathrm{~mm}$. The center of the QMB crystal was $\sim 60 \mathrm{~mm}$ off-center with the central axis of the Li target. The center of the Mo substrate was $\sim 15 \mathrm{~mm}$ off center with the center of the Li target. The diameter of the Li target was $\sim 50 \mathrm{~mm}$. To correct for different placements of the QMB and the substrate, a separate calibration was performed (see section 3.1) 


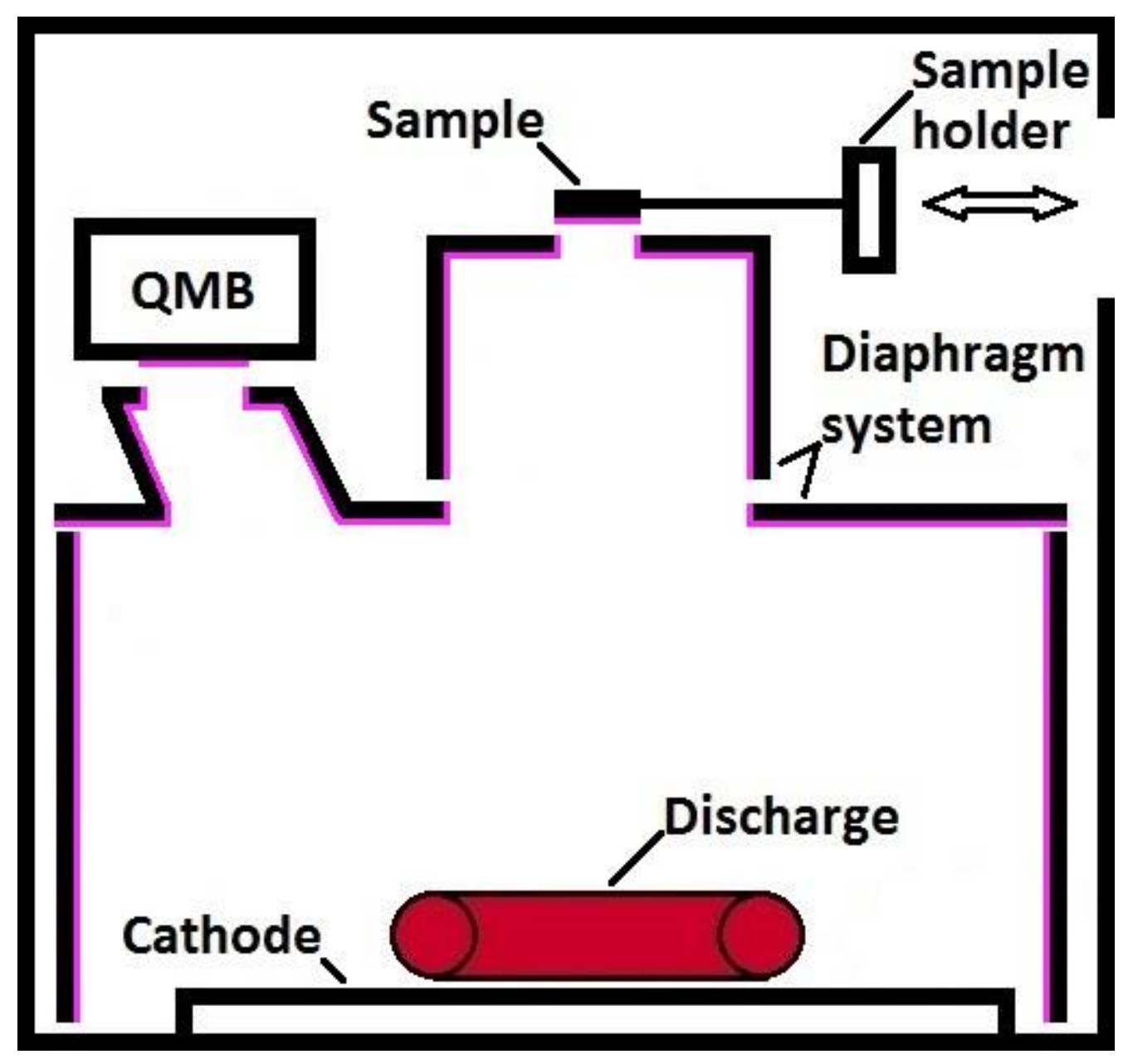

Fig. 7. A sketch of the setup in which Li films were deposited. Pink areas indicate places where Li could be deposited.

EBS was performed using the TANDEM accelerator in IPP Garching, with $4.0 \mathrm{MeV}$ protons at normal incidence angle. The scattering angle was $165^{\circ}$, and couldn't be changed due to technical limitations of the experimental setup. The cross section used for data analysis was an interpolation based on the data for $140^{\circ}, 150^{\circ}, 160^{\circ}$ and $170^{\circ}$ angles from [32]. An interpolation with the $160^{\circ}$ and $170^{\circ}$ data only, as well as with $170^{\circ}, 160^{\circ}$ and $150^{\circ}$ resulted in identical interpolated values within the uncertainties, and in this situation it was considered prudent to use more data, where available. A $300 \mu \mathrm{m}$ thick PIPS detector was used with a solid angle of $1.10 \pm 0.03 \mathrm{msr}$. The target is surrounded by a Farraday screen (with small holes for the incident beam and toward the detector) for accurate charge collection with an accuracy of about $3 \%$, the total ion charge accumulated in each measurement was $20 \mu \mathrm{C}$.

The time between deposition and analysis varied between one and three months, the films were kept in closed non-sealed containers in contact with atmospheric air, at room temperature (between 18 and $25{ }^{\circ} \mathrm{C}$ ), at $\sim 20 \%$ relative humidity. This time should have been more than sufficient to completely transform Li layers into $\mathrm{Li}_{2} \mathrm{CO}_{3}$. 


\section{Experimental results}

\subsection{Experimental EBS spectra}

Typical EBS spectra for $4 \mathrm{MeV}$ normal incidence protons at $165^{\circ}$ scattering angle for thin lithium films on molybdenum are shown in fig. 8a and 8b. Three peaks corresponding to lithium, carbon and oxygen can be distinguished on the Mo substrate signal. As one can expect from the cross section data, the oxygen peak is the most pronounced. It can be noted that in some areas of the film (fig 8a) peaks are rather wide with long low energy tails. In some other areas of the film (fig $8 \mathrm{~b}$ ), the peaks are narrow, without pronounced low-energy tails. Such tails can be caused either by diffusion of $\mathrm{Li}$ into the substrate, by an inhomogeneous thickness distribution of the Li2CO3 films, i.e. layer roughness [M. Mayer, Nuclear Instruments and Methods in Physics Research Section B: Beam Interactions with Materials and Atoms 194 (2002) 177], or by layer porosity. The pronounced low energy tails cannot result from Li diffusion into the substrate, as the temperature of the substrate was never higher than $350{ }^{\circ} \mathrm{C}$, where diffusion should still be negligible [64]. During magnetron deposition the energy of Li particles is not higher than $\sim 50 \mathrm{eV}$, which means that the films are deposited only on the surface and are not implanted into Mo. Porosity of the layer might result in a pronounced low energy front, but one could expect that in a film that fully reacted with atmospheric air, porosity would be relatively homogeneous over the whole layer, and so all measured areas would have a pronounced low energy front, rather than only some of them.
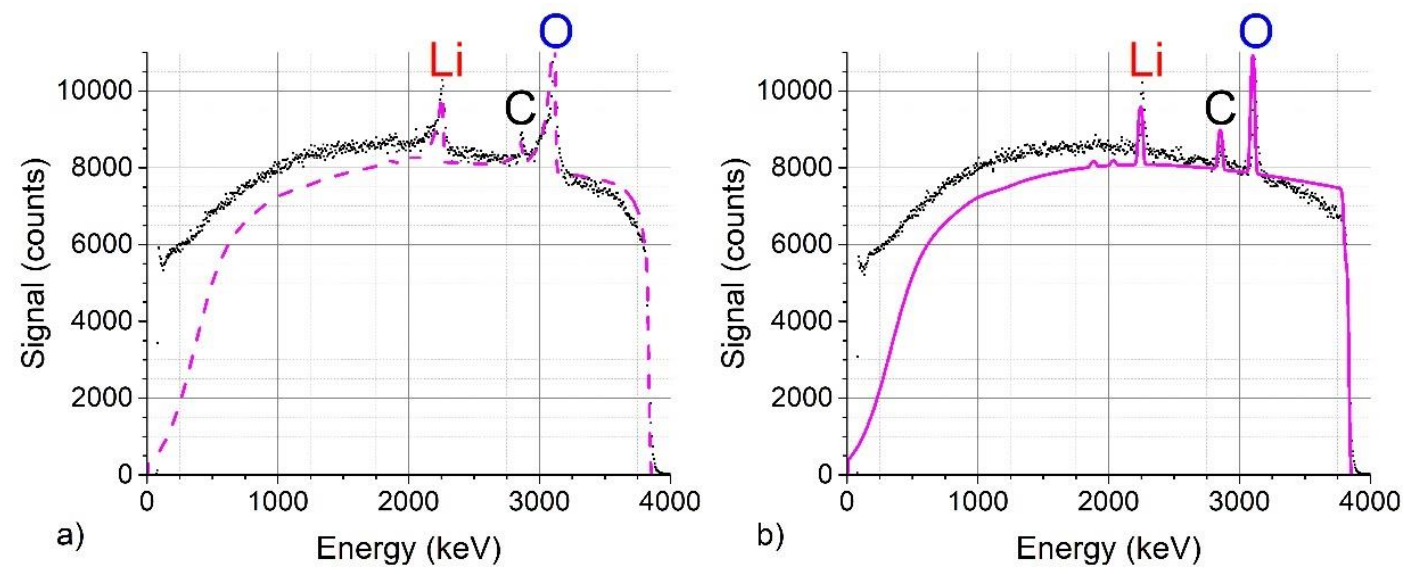

Fig. 8. Typical EBS spectra (4 MeV protons at normal incidence, $165^{\circ}$ scattering angle) of an ex-situ analysis of a thin Li film on molybdenum substrate. Film thickness about $\sim 270 \mathrm{~nm}$ assuming the density of $\mathrm{Li}_{2} \mathrm{CO}_{3}$ (corresponding to $210 \mathrm{~nm}$ initial Li thickness), see table 2, row 4. Dots are experimental data, magenta dashed line - SIMNRA modeling. Figure a) measurement in the point with a prominent low energy front of film peaks (corresponds to the second from the left green point in fig. 9), b) measurement in the point without a prominent low energy front of film peaks (corresponds to the third from the left green point in fig. 9).

One can see that the SIMNRA model does not provide a very good fit due to the poor handling of the Mo background signal. In order to obtain the amounts of $\mathrm{Li}, \mathrm{C}$ and $\mathrm{O}$, the Mo signal was interpolated using experimental data outside the peakthen subtracted from the signal. The resulting peaks were then integrated and modeled using SIMNRA, so the integrals of the modeled peaks were the same as the experimental values. Net counts, background signal, and 
uncertainties are given in table 3. Uncertainties were calculated based on statistical uncertainties of the net peak counts, the interpolated background signal, and the cross section data uncertainty for $4 \mathrm{MeV}$ energy [32].

Table 3. Net counts for $\mathrm{Li}, \mathrm{C}$, O peaks, interpolated background signal in typical EBS spectra of thin Li films on Mo, calculated uncertainties.

\begin{tabular}{|l|l|l|}
\hline Spectra & Fig 8a. & Fig 8b \\
\hline Li peak counts & 24500 & 11400 \\
\hline Li background counts & 454300 & 170000 \\
\hline Li uncertainty, \% & 3 & 4 \\
\hline C peak counts & 8500 & 7500 \\
\hline C background counts & 196700 & 174000 \\
\hline C uncertainty, \% & 6 & 6 \\
\hline O peak counts & 57900 & 22500 \\
\hline O background counts & 418400 & 155000 \\
\hline O uncertainty, \% & 1.2 & 2 \\
\hline
\end{tabular}

EBS was used to calibrate the QMB in-situ film thickness measurement system. To do this, a Li layer was deposited on a fresh quartz crystal and a Mo substrate in a typical deposition geometry and conditions for MD-2. The amounts of $\mathrm{Li}$ were then measured on both the crystal and the substrate using EBS with $2.7 \mathrm{MeV}$ protons (normal incidence, $165^{\circ}$ observation angle). The energy of $2.7 \mathrm{MeV}$ was used so the cross sections from [40] could be used directly without any interpolation. The selection of the cross section for such calibrations, where two quantities of $\mathrm{Li}$ in thin films are compared, does not create an additional error, as only the ratio of Li amounts in two measurements is important, and energy losses in the Li containing layer can be neglected. Additionally, at $2.7 \mathrm{MeV}$ p+ energy, SIMNRA simulations provided good fit for the Mo background signal. For the crystal itself, the quantity of Li calculated by QMB ( $950 \AA$ assuming metallic Li density) matched well with the data from EBS $\left(4.4 \times 10^{17}\right.$ atoms $/ \mathrm{cm}^{2}$ which is equal to $\sim 950 \AA$ assuming metallic Li atomic density). The ratio between the deposition on the Mo substrate and the QMB crystal was $~ 1.9$. This indicated that, despite Li atoms being light, the large distance between the magnetron target and the Mo substrate $(\sim 11 \mathrm{~cm})$ and the high discharge pressure $(4 \mathrm{~Pa})$, scattering during transport through the gas phase is not sufficient to homogenize the $\mathrm{Li}$ distribution. To make sure that the calibration remained the same, the discharge parameters in MD-2 are kept the same as much as possible. Repeated calibrations during a year after the first one produced similar ratios.

Using the SimTra [65] software, Li transport through the gas phase in the MD-2 installation was modeled; and the ratio of the amount of particles on the Mo substrate to the amount of particles on the QMB crystal was obtained to be $\sim 0.3$. The largest uncertainty in modeling the $\mathrm{Li}$ deposition distribution is the lack of reliable data on the directional distribution of Li particles sputtered from a liquid Li CPS target. Additionally, the code does not take into account the temperature dependent flux of evaporating particles, though it can be comparable with the flux of sputtered particles. Li evaporation can create vapor shielding near the Li target [66], which would significantly affect the transport of Li particles and their final distribution. Other effects, such as a microscopically curved profile of the CPS Li target caused by the capillary effects 
curving the surface of liquid Li could change the directional distribution of sputtered Li. Overall, this means that the final distribution of Li eroded from a liquid Li CPS target by plasma depends on many parameters and is rather uncertain. This makes useful the development of methods for measurement of quantities of $\mathrm{Li}$ in thin re-deposited layers for fusion devices with Li plasma facing components.

\subsection{Spatial inhomogeneity}

It was found after prolonged atmospheric exposure, that the thickness of $\mathrm{Li}$ films was inhomogeneous on the surface (fig. 9). In contrast to this the variation of the thickness of $\mathrm{W}$ films deposited in the same setup and conditions was smaller than $3 \%$, see fig. 9. It is assumed that the inhomogeneity of the Li films is due to chemical reactions of $\mathrm{Li}$ with atmospheric air. The initially homogeneous thin Li layer breaks apart when reacting with atmospheric air because the chemical processes produce mechanical tensions in the film. Different stages of the chemical reaction chain leading from initially deposited $\mathrm{Li}$ to the final $\mathrm{Li}_{2} \mathrm{CO}_{3}$ product can in principle produce both pulling and pushing forces. The resulting separate areas of the Li compound can be distributed non-homogeneously across the surface and have different thicknesses and surface geometries, such as curled up borders. Because of this, when analyzed with a fairly small diameter ion beam, a variation in thickness can be observed from point to point.

This inhomogeneity is also seen in scanning electron microscope (SEM) (fig. 10). A number of features can be seen on the surface of the film. A number of crystalline and droplet-like grown structures was observed on the surface of the film. These structures are likely to contain more lithium per surface area than the film itself. In addition to that, the film is covered in tears and ridges, where the film underwent strong mechanical stresses during its chemical transformations. All those features are likely to contribute strongly to the observed inhomogeneity of the film. 


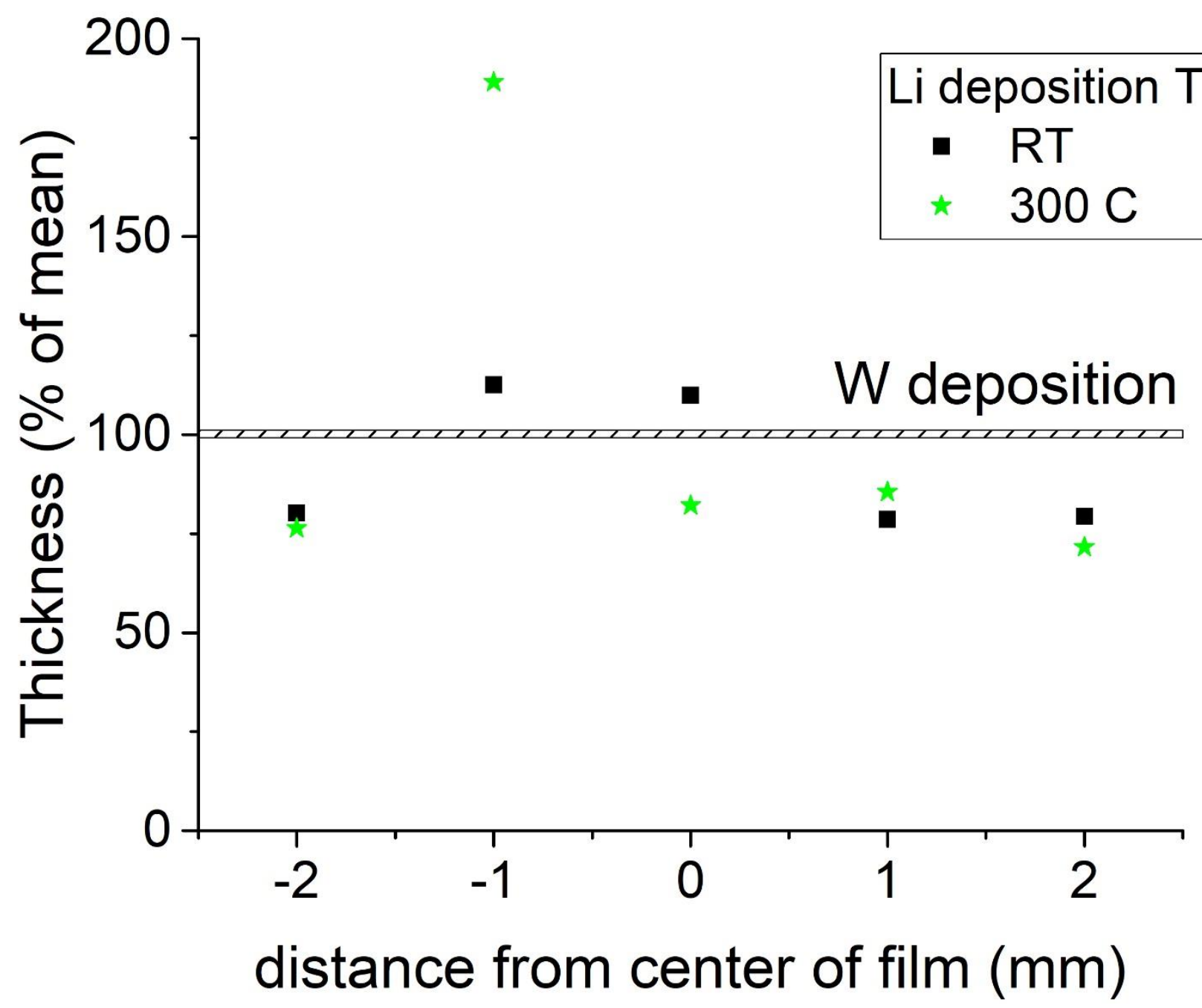

Fig. 9. Li thickness measured at various points of a deposited film on the surface. The variation of $W$ thickness deposited at the same conditions is given by a narrow shaded area. 


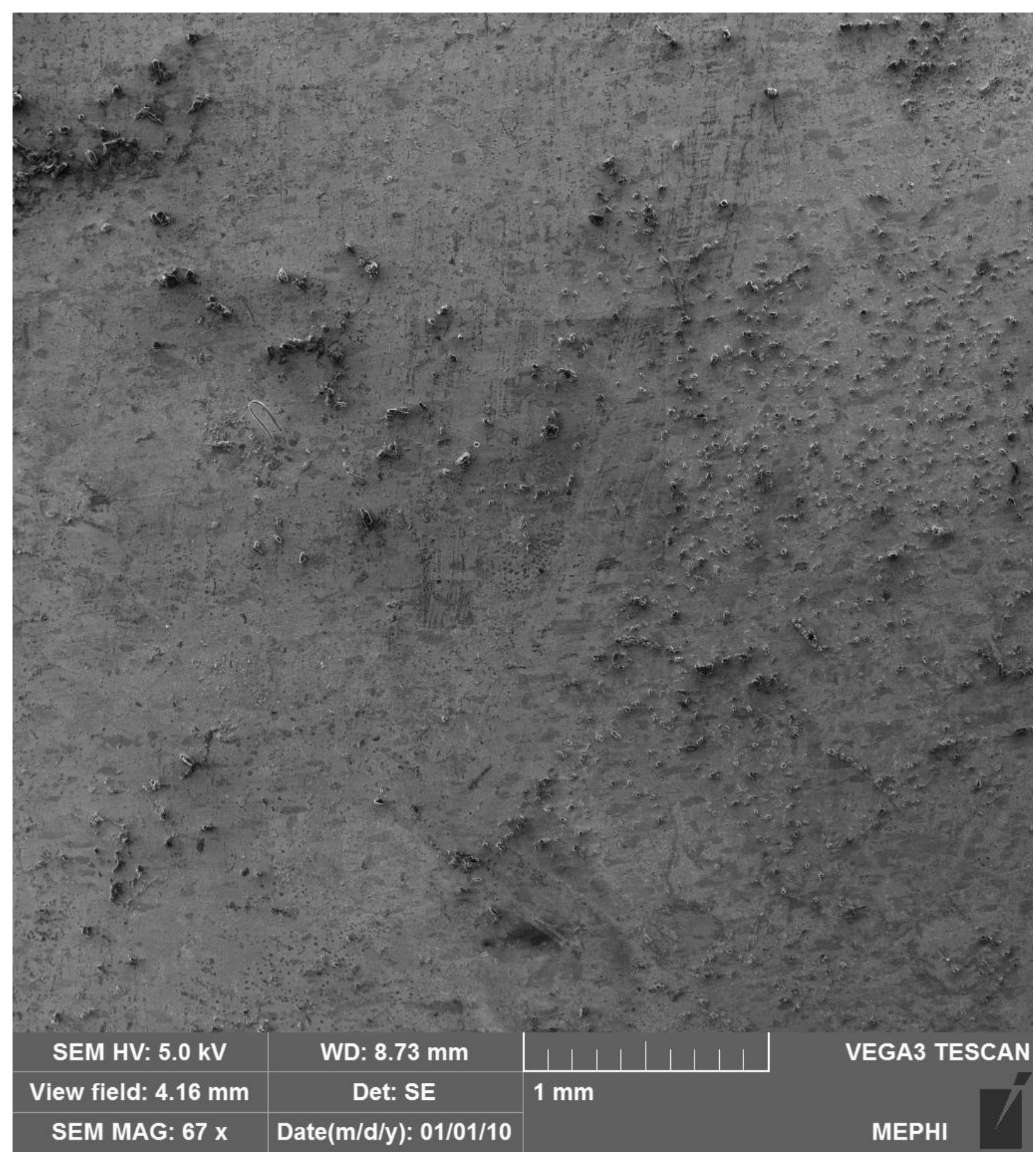

Fig. 10. SEM image in secondary electron (SE) mode of a Li layer deposited at room temperature.

If the amount of deposited $\mathrm{Li}$ is so small that no continuous film is formed on the surface, one can observe individual Li-containing crystal islands on the surface of the substrates (fig. 11). Formation of islands is only possible if the migration of Li atoms on the surface of the substrate is sufficiently fast. The distribution of the crystals is not homogeneous. The density and sizes of the islands are very different on different Mo grains, and smaller sizes correlate with smaller density. This might be connected with differences in surface free energies of grains with different orientations resulting in different interaction with $\mathrm{Li}$, or with different surface diffusivity of Li along the different grain orientations. 


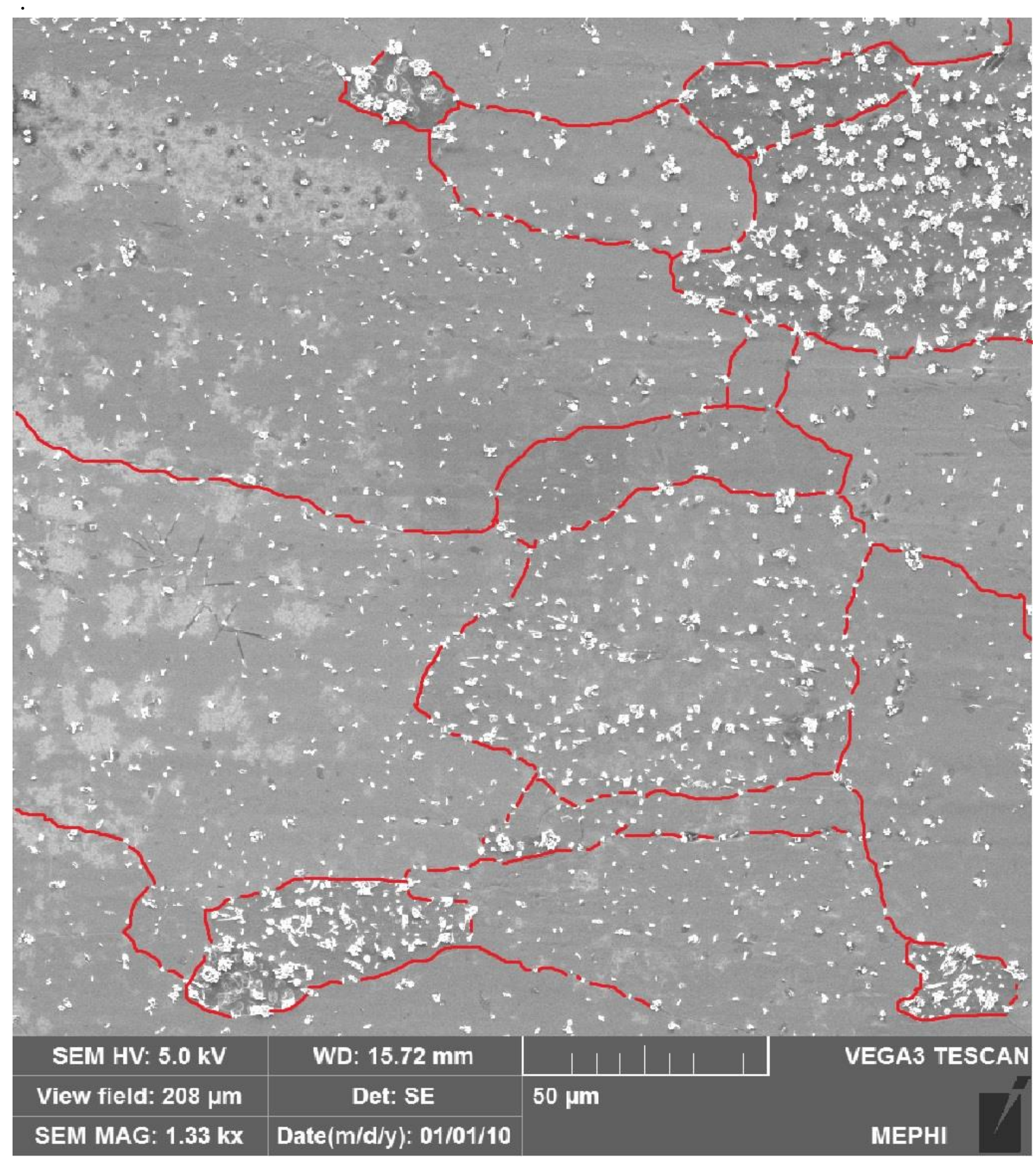

Fig. 11. Distribution of Li-containing crystal islands on Mo surface at a very low amount of deposited Li. Red lines to guide the eye along the grain boundaries.

The inhomogeneity of Li films after exposure to atmospheric air presents a lower boundary on spatial resolution of Li content analysis, generated by the properties of the Li films themselves, rather than specific issues of the EBS method. In practical terms, averaging over a 5-millimeterlong area resulted in less than $30 \%$ fluctuations for the Li content in all cases.

\subsection{Chemical composition and evaporation rate}


Observed compositions of Li films on molybdenum are shown in table 4. The data presented in the table were averaged over five measurements for each sample, to account for the inhomogeneities of the Li films produced by contact with atmospheric air. Each EBS measurement was one millimeter apart from the others (examples in fig. 9). Measurements in all five points were treated as separate instances of measuring the same quantity of Li. The main component of the given uncertainty is the fluctuation of multiple measurements, generated due to non-uniformity in film composition, total thickness in each measured point.

The films exhibit elemental compositions close to that expected from $\mathrm{Li}_{2} \mathrm{CO}_{3}$. The thicknesses in $\mathrm{nm}$ were calculated based on the total $\mathrm{Li}$ content, assuming $\mathrm{Li}_{2} \mathrm{CO}_{3}$ density and a homogeneous continuous film on the flat surface. The carbon content strongly varies from experiment to experiment being both below and above the stoichiometric value. Overabundance of $\mathrm{C}$ for RT and $300{ }^{\circ} \mathrm{C}$ can be perhaps explained by carbon introduced during sample transport, or not being removed during substrate annealing at $1230^{\circ} \mathrm{C}$. The concentrations of $\mathrm{Li}$ are usually somewhat below, while those for $\mathrm{O}$ are somewhat above the stoichiometric values. Nevertheless, the use of $\mathrm{O}$ is far more reliable than the use of $\mathrm{C}$. Therefore, rough quantitative estimations of the $\mathrm{Li}$ content can be made using measurements of the $\mathrm{O}$ content, while estimates using experiments with $\mathrm{C}$ are drastically uncertain and cannot be recommended for the evaluation of the Li content in deposited films.

Table 4. Elemental composition of Li-containing layers deposited on Mo substrate at different substrate temperatures (shown in the leftmost column)

\begin{tabular}{|l|l|c|c|c|}
\hline T deposition, ${ }^{\circ} \mathrm{C}$ & $\begin{array}{l}\text { Thickness, } \mathrm{nm} \\
\left(\text { at } \mathrm{Li}_{2} \mathrm{CO}_{3} \text { density) }\right.\end{array}$ & $\mathrm{Li}$, at. \% & C, at. \% & O, at. \% \\
\hline $\mathrm{Li}_{2} \mathrm{CO}_{3}$, theoretical & \multicolumn{1}{|c|}{ n. } & 33 & 17 & 50 \\
\hline $\mathrm{RT}$ & $200 \pm 20$ & $26 \pm 4$ & $27 \pm 5$ & $47 \pm 6$ \\
\hline 200 & $280 \pm 120$ & $24 \pm 11$ & $10 \pm 5$ & $66 \pm 12$ \\
\hline 260 & $360 \pm 70$ & $28 \pm 7$ & $5.3 \pm 0.9$ & $66 \pm 7$ \\
\hline 300 & $270 \pm 50$ & $27 \pm 5$ & $21 \pm 3$ & $52 \pm 6$ \\
\hline 350 & $50 \pm 12$ & $21 \pm 5$ & Below detection limit & $79 \pm 5$ \\
\hline
\end{tabular}

\section{Conclusions}

The potential of Elastic Backscattering Spectrometry (EBS) for ex-situ analysis of lithium films on fusion-relevant substrates was discussed. It is shown that despite its low atomic number, it is possible to quantitatively measure the Li content even in relatively thin Li layers on heavy substrates. Analyses of the scattering cross sections from Li and from various substrate elements demonstrated that the best energy for analysis of lithium on molybdenum and tungsten substrates is $\sim 4.0 \mathrm{MeV}$ and on carbon $-2 \mathrm{MeV}$. These energies give the highest ratio of the Li signal to the substrate signal. Experimental results demonstrated that films as thin as $\sim 50 \mathrm{~nm}$ can be analyzed on a molybdenum substrate. It was observed that non-homogeneity caused by atmospheric exposure is the primary source of uncertainty in evaluating the Li content, and not the limitations of the EBS method.

Modeling of EBS predicted that, depending on the material of the substrate, energies of protons, and analysis methods used, Li layers as thick as $600 \mu \mathrm{m}$ can be analyzed by means of EBS. 
Prolonged atmospheric exposure leads to a 5-fold decrease of the maximum amount of Li that can be analyzed due to reactions with carbon and oxygen with final formation of $\mathrm{Li}_{2} \mathrm{CO}_{3}$. Overall, flaking and cracking due to exposure to atmospheric air are far more likely to be the limiting factor than limitations of the EBS method.

It was shown that the amount of $\mathrm{Li}$ on the surface after long contact with air can be roughly estimated using EBS from oxygen in the film, while EBS signals from carbon show large scatter.

It was experimentally observed that the thickness of Li films is non-uniform over the surface of the substrate due to reactions with air, therefore several measurements are to be made to obtain a correct surface density of lithium by means of EBS. It was observed experimentally that Li atoms form islands on the surface of the substrate if the amount of deposited Li is very low. The sizes and densities of islands on grains of different orientations are different.

\section{Acknowledgements}

This work was supported by the Russian Science Foundation grant №18-72-00213. Upgrade of the facility for film deposition was performed thanks to grant №.14.Y26.31.0008 given by the Ministry of Education and Science of the Russian Federation The authors thank Alexander Poskakalov for his help in SEM analysis, and J. Dorner and M. Fußeder from IPP Garching for their help in EBS analysis.

\section{References}

[1] H.W. Kugel, M.G. Bell, J.P. Allain, R.E. Bell, S. Ding, S.P. Gerhardt, et al., NSTX plasma response to lithium coated divertor, J. Nucl. Mater. 415 (2011) S400-S404. doi:10.1016/j.jnucmat.2010.12.016.

[2] S.A. Sabbagh, J.-W. Ahn, J. Allain, R. Andre, A. Balbaky, R. Bastasz, et al., Overview of physics results from the conclusive operation of the National Spherical Torus Experiment, Nucl. Fusion. 53 (2013) 104007. doi:10.1088/0029-5515/53/10/104007.

[3] D.. Ruzic, M.M.. Allain, R.. Budny, The effect of lithium wall conditioning in TFTR on plasma-surface interactions, J. Nucl. Mater. 266-269 (1999) 1303-1308. doi:10.1016/S0022-3115(98)00863-0.

[4] G.Z. Zuo, J.S. Hu, J.G. Li, Z. Sun, D.K. Mansfield, L.E. Zakharov, Lithium coating for Hmode and high performance plasmas on EAST in ASIPP, J. Nucl. Mater. 438 (2013) S90S95. doi:10.1016/j.jnucmat.2013.01.014.

[5] S.V. Mirnov, A.M. Belov, N.T. Djigailo, A.S. Dzhurik, S.I. Kravchuk, V.B. Lazarev, et al., Experimental test of the system of vertical and longitudinal lithium limiters on T-11M tokamak as a prototype of plasma facing components of a steady-state fusion neutron source, Nucl. Fusion. 55 (2015) 123015. doi:10.1088/0029-5515/55/12/123015.

[6] E. Schmidt, K. Ritter, K. Gärtner, E. Wendler, Investigation of Li/Nb-sublattices in ion implanted LiNbO 3 by RBS and NRA in channelling configuration, Nucl. Instruments Methods Phys. Res. Sect. B Beam Interact. with Mater. Atoms. 409 (2017) 126-132. doi:10.1016/j.nimb.2017.03.111.

[7] V. Pericoli-Ridolfini, M.L. Apicella, G. Mazzitelli, O. Tudisco, R. Zagorski, F.T.U. Team, Edge properties with the liquid lithium limiter in FTU - experiment and transport modelling, Plasma Phys. Control. Fusion. 49 (2007) S123-S135. doi:10.1088/0741- 
[8] G.Z. Zuo, J. Ren, J.S. Hu, Z. Sun, Q.X. Yang, J.G. Li, et al., Liquid lithium surface control and its effect on plasma performance in the HT-7 tokamak, Fusion Eng. Des. 89 (2014) 2845-2852. doi:10.1016/j.fusengdes.2014.05.020.

[9] I.E. Lyublinski, A. V. Vertkov, M.Y. Zharkov, V. V. Semenov, S. V. Mirnov, V.B. Lazarev, et al., Status of design and experimental activity on module of lithium divertor for KTM tokamak, Fusion Eng. Des. 88 (2013) 1862-1865. doi:10.1016/j.fusengdes.2013.05.103.

[10] D.N. Ruzic, M. Szott, C. Sandoval, M. Christenson, P. Fiflis, S. Hammouti, et al., Flowing liquid lithium plasma-facing components - Physics, technology and system analysis of the LiMIT system, Nucl. Mater. Energy. 12 (2017) 1324-1329. doi:10.1016/j.nme.2017.06.001.

[11] H.W. Kugel, J.P. Allain, M.G. Bell, R.E. Bell, A. Diallo, R. Ellis, et al., NSTX plasma operation with a Liquid Lithium Divertor, Fusion Eng. Des. 87 (2012) 1724-1731. doi:10.1016/j.fusengdes.2011.07.010.

[12] S. Brezinsek, A. Widdowson, M. Mayer, V. Philipps, P. Baron-Wiechec, J.W. Coenen, et al., Beryllium migration in JET ITER-like wall plasmas, Nucl. Fusion. 55 (2015) 063021. doi:10.1088/0029-5515/55/6/063021.

[13] M. Rubel, J.P. Coad, D. Hole, Accelerator-based ion beam analysis of fusion reactor materials, Vacuum. 78 (2005) 255-261. doi:10.1016/j.vacuum.2005.01.109.

[14] K. Krieger, J. Likonen, M. Mayer, R. Pugno, V. Rohde, E. Vainonen-Ahlgren, Tungsten redistribution patterns in ASDEX Upgrade, J. Nucl. Mater. 337-339 (2005) 10-16. doi:10.1016/j.jnucmat.2004.09.044.

[15] A.M. Capece, J.P. Roszell, C.H. Skinner, B.E. Koel, Effects of temperature and surface contamination on D retention in ultrathin Li films on TZM, J. Nucl. Mater. 463 (2015) 1177-1180. doi:10.1016/j.jnucmat.2014.10.048.

[16] Y.M.Y.M. Gasparyan, A.S. Popkov, S.A. Krat, A.A. Pisarev, Y.A.Y.A. Vasina, I.E. Lyublinski, et al., Deuterium release from Li-D films exposed to atmospheric gases, Fusion Eng. Des. 117 (2017) 163-167. doi:10.1016/j.fusengdes.2016.07.025.

[17] I.E. Lyublinski, A. V Vertkov, V.A. Evtikhin, Application of lithium in systems of fusion reactors. 1. Physical and chemical properties of lithium, Plasma Devices Oper. 17 (2009) 42-72. doi:10.1080/10519990802703277.

[18] H. Kitaura, H. Zhou, Reaction and degradation mechanism in all-solid-state lithium-air batteries, Chem. Commun. 51 (2015) 17560-17563. doi:10.1039/C5CC07884A.

[19] X. Liu, J. Liu, Effect of air humidity on microstructure and phase composition of lithium deuteride corrosion products, Corros. Sci. 115 (2017) 129-134. doi:10.1016/j.corsci.2016.11.017.

[20] S. V Mirnov, N.T. Djigailo, A.N. Shcherbak, Physicochemical technique for determining absolute lithium amount in lithium films covering diagnostic targets in tokamak chambers, Probl. At. Sci. Technol. Ser. Thermonucl. Fusion. 41 (2018) 53-56. doi:10.21517/02023822-2017-41-1-53-56.

[21] W.R. Wampler, Ion beam analysis for fusion energy research, Nucl. Instruments Methods Phys. Res. Sect. B Beam Interact. with Mater. Atoms. 219-220 (2004) 836-845. doi:10.1016/j.nimb.2004.01.173. 
[22] D. Mueller, a. L. Roquemore, M. Jaworski, C.H. Skinner, J. Miller, a. Creely, et al., In situ measurement of low-Z material coating thickness on high $\mathrm{Z}$ substrate for tokamaksa), Rev. Sci. Instrum. 85 (2014) 11E821. doi:10.1063/1.4893425.

[23] F. Bedoya, K.B. Woller, D.G. Whyte, Study of the properties of thin Li films and their relationship with He plasmas using ion beam analysis in the DIONISOS experiment, Rev. Sci. Instrum. 89 (2018) 10J106. doi:10.1063/1.5034240.

[24] J.P.S. Loureiro, F.L. Tabarés, H. Fernandes, C. Silva, R. Gomes, E. Alves, et al., Behavior of liquid Li-Sn alloy as plasma facing material on ISTTOK, Fusion Eng. Des. 117 (2017) 208-211. doi:10.1016/j.fusengdes.2016.12.031.

[25] M.L. Apicella, G. Mazzitelli, V. Pericoli Ridolfini, V. Lazarev, A. Alekseyev, A. Vertkov, et al., First experiments with lithium limiter on FTU, J. Nucl. Mater. 363-365 (2007) 1346-1351. doi:http://dx.doi.org/10.1016/j.jnucmat.2007.01.237.

[26] J.S. Hu, J. Ren, Z. Sun, G.Z. Zuo, Q.X. Yang, J.G. Li, et al., An overview of lithium experiments on HT-7 and EAST during 2012, Fusion Eng. Des. 89 (2014) 2875-2885. doi:10.1016/j.fusengdes.2014.06.015.

[27] S. V Mirnov, A.M. Belov, N.T. Djigailo, A.N. Kostina, V.B. Lazarev, I.E. Lyublinski, et al., Recent lithium experiments in tokamak T-11M, J. Nucl. Mater. 438, Suppl (2013) S224-S228. doi:http://dx.doi.org/10.1016/j.jnucmat.2013.01.032.

[28] S. Bashkin, H.T. Richards, Proton Bombardment of the Lithium Isotopes, Phys. Rev. 84 (1951) 1124-1129. doi:10.1103/PhysRev.84.1124.

[29] G.P. Johnston, D.G. Sargood, Angular distributions in the reaction 6Li(p, 3He)4He, Nucl. Phys. A. 224 (1974) 349-357. doi:10.1016/0375-9474(74)90692-7.

[30] F. Bertrand, G. Grenier, J. Pornet, 6Li(p,alpha)3He, 6Li(d,alpha)4He, 6Li(d,p0)7Li, $6 \mathrm{Li}(\mathrm{d}, \mathrm{p} 1) 7 \mathrm{Li}^{*}$ reaction investigation in the energy interval from $300 \mathrm{keV}$ to $1000 \mathrm{keV}$, 1968.

[31] Ion Beam Analysis Nuclear Data Library (IBANDL), IAEA. (2017). wwwnds.iaea.org/exfor/ibandl.htm.

[32] V. Paneta, A. Kafkarkou, M. Kokkoris, A. Lagoyannis, Differential cross-section measurements for the $7 \mathrm{Li}(\mathrm{p}, \mathrm{p} 0) 7 \mathrm{Li}, 7 \mathrm{Li}(\mathrm{p}, \mathrm{p} 1) 7 \mathrm{Li}, 7 \mathrm{Li}(\mathrm{p}, \alpha 0) 4 \mathrm{He}, 19 \mathrm{~F}(\mathrm{p}, \mathrm{p} 0) 19 \mathrm{~F}$, $19 \mathrm{~F}(\mathrm{p}, \alpha 0) 16 \mathrm{O}$ and $19 \mathrm{~F}(\mathrm{p}, \alpha 1,2) 16 \mathrm{O}$ reactions, Nucl. Instruments Methods Phys. Res. Sect. B Beam Interact. with Mater. Atoms. 288 (2012) 53-59. doi:10.1016/j.nimb.2012.07.020.

[33] P. Paul, K.P. Lieb, The excited state at $25 \mathrm{MeV}$ in Be8, Nucl. Phys. 53 (1964) 465-476. doi:10.1016/0029-5582(64)90626-1.

[34] A.J. Elwyn, R.E. Holland, C.N. Davids, L. Meyer-Schutzmeister, J.E. Monahan, F.P. Mooring, et al., Absolute cross sections for deuteron-induced reactions on $6 \mathrm{Li}$ at at energies below $1 \mathrm{MeV}$, Phys. Rev. C. 16 (1977) 1744-1756. doi:10.1103/PhysRevC.16.1744.

[35] A.J. Elwyn, R.E. Holland, C.N. Davids, J.E. Monahan, F.P. Mooring, W. Ray, Cross sections for the $6 \mathrm{Li}(3 \mathrm{He}, \mathrm{p})$ reaction at energies below $2 \mathrm{MeV}$, Phys. Rev. C. 22 (1980) 1406-1419. doi:10.1103/PhysRevC.22.1406.

[36] J.P. Schiffer, T.W. Bonner, R.H. Davis, F.W. Prosser, Study of the Reaction Mechanism for (He3,p) Reactions with Li6, B10 , and C13, Phys. Rev. 104 (1956) 1064-1068. doi:10.1103/PhysRev.104.1064. 
[37] B. Vignon, E. Ligeon, J.P. Longequeue, Étude des réactions $6 \mathrm{Li}(3 \mathrm{He}, \mathrm{p})$ et $6 \mathrm{Li}(3 \mathrm{He}, \mathrm{p} \alpha \alpha)$ en dessous de $2 \mathrm{MeV}$, J. Phys. 30 (1969) 913-917. doi:10.1051/jphys:01969003001112091300.

[38] U. Fasoli, D. Toniolo, G. Zago, Elastic and inelastic scattering of protons by7Li in the energy interval $(3.0 \div 5.5) \mathrm{MeV}$, Nuovo Cim. 34 (1964) 542-551. doi:10.1007/BF02749997.

[39] K. Kilian, G. Clausnitzer, W. Dürr, D. Fick, R. Fleischmann, H.M. Hofmann, Untersuchung der reaktionen 7Li(p, p0)7Li, 7Li(p, p1)7Li* und7Le(p, $\alpha) 4 \mathrm{He}$ MIT polarisierten protonen der energie 2.7 BIS 10.6 MeV, Nucl. Phys. A. 126 (1969) 529-544. doi:10.1016/0375-9474(69)90845-8.

[40] P.R. Malmberg, Elastic Scattering of Protons from 7Li, Phys. Rev. 101 (1956) 114-118. doi:10.1103/PhysRev.101.114.

[41] A.F. Gurbich, SigmaCalc recent development and present status of the evaluated crosssections for IBA, Nucl. Instruments Methods Phys. Res. Sect. B Beam Interact. with Mater. Atoms. 371 (2016) 27-32. doi:10.1016/j.nimb.2015.09.035.

[42] R.. Harris, G.. Phillips, C. Miller Jones, Phase shift analysis of the elastic scattering of protons from oxygen, Nucl. Phys. 38 (1962) 259-280. doi:10.1016/0029-5582(62)910337.

[43] R. Gleyvod, N.P. Heydenburg, I.M. Naqib, Elastic and inelastic scattering of protons by Li7, Nucl. Phys. 63 (1965) 650-656. doi:10.1016/0029-5582(65)90752-2.

[44] M. Mayer, SIMNRA User's Guide, Max-Planck-Institut für Plasmaphysik, Germany, Garching, Germany, 1997.

[45] J.F. Ziegler, SRIM.org, (n.d.).

[46] T. Furukawa, Y. Hirakawa, H. Kondo, T. Kanemura, E. Wakai, Chemical reaction of lithium with room temperature atmosphere of various humidities, Fusion Eng. Des. 98-99 (2015) 2138-2141. doi:10.1016/j.fusengdes.2014.11.019.

[47] Y. Sun, Y. Li, J. Sun, Y. Li, A. Pei, Y. Cui, Stabilized Li3N for efficient battery cathode prelithiation, Energy Storage Mater. 6 (2017) 119-124. doi:10.1016/j.ensm.2016.10.004.

[48] G. Weber, E. Sciora, J. Guichard, F. Bouyer, I. Bezverkhyy, F. Bernard, et al., New insight on the lithium hydride-water vapor reaction system, Int. J. Hydrogen Energy. 43 (2018) 22557-22567. doi:10.1016/j.ijhydene.2018.10.089.

[49] J.P. Tonks, M.O. King, E.C. Galloway, J.F. Watts, Corrosion studies of LiH thin films, J. Nucl. Mater. 484 (2017) 228-235. doi:10.1016/j.jnucmat.2016.12.008.

[50] L.N. Dinh, C.M. Cecala, J.H. Leckey, M. Balooch, The effects of moisture on LiD single crystals studied by temperature-programmed decomposition, J. Nucl. Mater. 295 (2001) 193-204. doi:10.1016/S0022-3115(01)00548-7.

[51] G. Zhuang, Y. Chen, P.N. Ross, The reaction of lithium with carbon dioxide studied by photoelectron spectroscopy, Surf. Sci. 418 (1998) 139-149. doi:10.1016/S00396028(98)00710-9.

[52] V.I. Subbotin, M.N. Arnoldovv, M.N. Ivanovskiy, A.A. Mosin, A.A. Tarbov, Lithium (in Russian), IZDAT, Moscow, 1999. http://www.rfbr.ru/rffi/ru/books/o_66730.

[53] J.M. McEnaney, A.R. Singh, J.A. Schwalbe, J. Kibsgaard, J.C. Lin, M. Cargnello, et al., Ammonia synthesis from $\mathrm{N} 2$ and $\mathrm{H} 2 \mathrm{O}$ using a lithium cycling electrification strategy at 
atmospheric pressure, Energy Environ. Sci. 10 (2017) 1621-1630. doi:10.1039/C7EE01126A.

[54] H.A. Mosqueda, C. Vazquez, P. Bosch, H. Pfeiffer, Chemical Sorption of Carbon Dioxide (CO 2 ) on Lithium Oxide (Li 2 O), Chem. Mater. 18 (2006) 2307-2310. doi:10.1021/cm060122b.

[55] W. Taifan, J.-F. Boily, J. Baltrusaitis, Surface chemistry of carbon dioxide revisited, Surf. Sci. Rep. 71 (2016) 595-671. doi:10.1016/j.surfrep.2016.09.001.

[56] Z. Zhao, P. Fu, B. Zhao, Studies on Reaction Kinetics of LiOH for Absorbing CO2, in: 2009 Asia-Pacific Power Energy Eng. Conf., IEEE, 2009: pp. 1-4. doi:10.1109/APPEEC.2009.4918790.

[57] J.F. Ziegler, M.D. Ziegler, J.P. Biersack, SRIM - The stopping and range of ions in matter (2010), Nucl. Instruments Methods Phys. Res. Sect. B Beam Interact. with Mater. Atoms. 268 (2010) 1818-1823. doi:10.1016/j.nimb.2010.02.091.

[58] S.A. Krat, Y.M. Gasparyan, A.S. Popkov, A.A. Pisarev, Time-resolved studies of deuterium release from lithium films exposed to water vapor, Fusion Eng. Des. 124 (2017) 333-337. doi:10.1016/j.fusengdes.2017.03.105.

[59] W. Ding, L.Q. Shi, X.G. Long, S.Z. Luo, S.M. Peng, B. Zhang, et al., Cross-section for $\mathrm{D}(\mathrm{p}, \mathrm{p}) \mathrm{D}$ elastic scattering from 1.8 to $3.2 \mathrm{MeV}$ at the laboratory angles of $155^{\circ}$ and $165^{\circ}$, Nucl. Instruments Methods Phys. Res. Sect. B Beam Interact. with Mater. Atoms. 267 (2009) 2341-2344. doi:10.1016/j.nimb.2009.03.108.

[60] R.A. Langley, Techniques for studying hydrogen and helium together in materials: ion backscattering and nuclear microanalysis, in: J.S. Walson, F.W. Wiffen (Eds.), Proc. Int. Conferernce Radiat. Eff. Tritium Technol. Fusion React., US Dept. of Commerce, Springfield, VA, USA, 1976: p. 158.

[61] V.K. Alimov, M. Mayer, J. Roth, Differential cross-section of the D(3He,p)4He nuclear reaction and depth profiling of deuterium up to large depths, Nucl. Instruments Methods Phys. Res. Sect. B Beam Interact. with Mater. Atoms. 234 (2005) 169-175. doi:http://dx.doi.org/10.1016/j.nimb.2005.01.009.

[62] S.A. Krat, Y.M. Gasparyan, A.S. Popkov, A.A. Pisarev, Deuterium release from lithiumdeuterium films, deposited in the magnetron discharge, Vacuum. 105 (2014) 111-114. doi:10.1016/j.vacuum.2014.01.006.

[63] S. V Mirnov, V.B. Lazarev, S.M. Sotnikov, V.A. Evtikhin, I.E. Lyublinski, A. V Vertkov, Li-CPS limiter in tokamak T-11M, in: Fusion Eng. Des., 2003: pp. 455-465. doi:10.1016/S0920-3796(03)00018-8.

[64] C.H. Wu, The diffusion of lithium in molybdenum, J. Chem. Phys. 62 (1975) 4589-4591. doi:10.1063/1.430431.

[65] K. Van Aeken, S. Mahieu, D. Depla, The metal flux from a rotating cylindrical magnetron: a Monte Carlo simulation, J. Phys. D. Appl. Phys. 41 (2008) 205307. doi:10.1088/0022-3727/41/20/205307.

[66] T.W. Morgan, P. Rindt, G.G. van Eden, V. Kvon, M.A. Jaworksi, N.J.L. Cardozo, Liquid metals as a divertor plasma-facing material explored using the Pilot-PSI and Magnum-PSI linear devices, Plasma Phys. Control. Fusion. 60 (2018) 14025. doi:10.1088/13616587/aa86cd. 